\title{
Killing the Priest-King: Addressing Egalitarianism in the Indus Civilization
}

\author{
Adam S. Green ${ }^{1}$ \\ Published online: 16 September 2020 \\ (C) The Author(s) 2020
}

\begin{abstract}
The cities of the Indus civilization were expansive and planned with large-scale architecture and sophisticated Bronze Age technologies. Despite these hallmarks of social complexity, the Indus lacks clear evidence for elaborate tombs, individualaggrandizing monuments, large temples, and palaces. Its first excavators suggested that the Indus civilization was far more egalitarian than other early complex societies, and after nearly a century of investigation, clear evidence for a ruling class of managerial elites has yet to materialize. The conspicuous lack of political and economic inequality noted by Mohenjo-daro's initial excavators was basically correct. This is not because the Indus civilization was not a complex society, rather, it is because there are common assumptions about distributions of wealth, hierarchies of power, specialization, and urbanism in the past that are simply incorrect. The Indus civilization reveals that a ruling class is not a prerequisite for social complexity.
\end{abstract}

Keywords Inequality · Indus civilization · Urbanization · Class · Stratification · Collective action · Heterarchy

\section{Introduction}

....there is nothing that we know of in prehistoric Egypt or Mesopotamia or anywhere else in Western Asia to compare with the well-built baths and commodious houses of the citizens of Mohenjo-daro. In those countries, much money and thought were lavished on the building of magnificent temples for the gods and on palaces and tombs of kings, but the rest of the people seemingly had to content themselves with insignificant dwellings of mud. In the Indus Valley, the picture is reversed, and the finest structures are those erected

Adam S. Green

ag952@cam.ac.uk

1 McDonald Institute for Archaeological Research, University of Cambridge, Downing Street, Cambridge CB2 3ER, UK 
for the convenience of the citizens. Temples, palaces, and tombs there may of course have been, but if so, they are either still undiscovered or so like other edifices as not to be readily distinguishable from them.

-Sir John Marshall, Preface to Mohenjo-daro and the Indus Civilization, 1931, p. vi

The archaeologists who first investigated the Indus civilization thought it diverged sharply from contemporary societies in Egypt and Mesopotamia (Marshall 1931, p. xi). For nearly a century, archaeologists have made a concerted effort to close this gap and make the Indus seem more "normal" in comparison with other complex societies. This is especially true with respect to inequality-specifically, stratification in the distribution of wealth and hierarchies of political power. In my view, these efforts have been largely unsuccessful. Marshall's observation was basically correct; attempts to refute it have been based on the theoretical assumption that all social complexity entails stratified social relations, rather than a critical interpretation of the empirical evidence. I argue that the widespread distribution of production activities and wealth in Indus cities indicates that the stratification of wealth and power, particularly in the hands of a ruling class who monopolized resources and dictated the production activities of everyone else, was absent from the Indus civilization.

Indus cities (c. 2600-1900 BC) were expansive and planned, with large-scale architecture and sophisticated early technologies—writing, metallurgy, weights and measures, and seals - that matched those from contemporaneous societies in Egypt and Mesopotamia. And yet, it has long been noted that Indus cities lack the tombs, palaces, and aggrandizing art that characterize other early complex societies (e.g., Fairservis 1967). These lines of evidence are essential to the comparative study of complex societies and particularly to the analysis of past inequalities in wealth and power (e.g., Feinman 1995; Feinman and Marcus 1998; Smith 2012). Their absence in the Indus suggests that the forms of inequality that we would expect to find if a class of ruling nobles managed society were limited or absent in Indus cities. Given that complex societies have often been defined by the presence of such stratification (e.g., Trigger 2003, p. 46), the perception that the absence of a ruling class in the Indus civilization risked its omission from comparative debates about the emergence of social complexity gained ground. In response, there arose an implicit argument that the Indus was indeed exceptional, not because it lacked a ruling class, but because to fully appreciate its political economy required an exceptional set of criteria (e.g., Kenoyer 1998). Ironically, this exceptionality led to its exclusion from comparative studies anyway (e.g., Cork 2011; Petrie 2019; Wright 2010). This is unfortunate, because the theoretical challenges brought about by Indus egalitarianism foreshadowed broader problems with traditional assumptions about distributions of wealth, hierarchies of power, specialization, and urbanism that have plagued comparative research on social complexity.

Despite considerable growth in our knowledge of Indus technologies (e.g., Kenoyer 1996; Miller 2007; Prabhakar 2018; Vidale 2000; Wright 1991) and environments (e.g., Madella and Fuller 2006; Petrie et al. 2017; Wright et al. 2008), no clear evidence of a ruling class has been recovered. Mohenjo-daro's first excavators 
explicitly grappled with empirical patterns that contradicted the idea that the Indus was under the control of a political hierarchy, such as the widespread availability of luxuries (e.g., private bathing platforms and commodious houses) that in Egypt and Mesopotamia were restricted to palace contexts (Marshall 1931, p. vi); for subsequent researchers the problem of Indus inequality largely receded from view. This is unfortunate, because there had been a time when the archaeology of the Indus had a significant influence on the broader comparative literature on social complexity. In the original edition of The Most Ancient East, Childe (1929) argued that the Indus civilization may have been the world's primary font of urbanization, perhaps based on impressions of Marshall's excavations at Mohenjo-daro in the 1920s. Following these brief experiments with the idea of Indus egalitarianism, scholars acted quickly to normalize the Indus within the evolutionary typologies that came to play such a strong role in comparative archaeology over the 20th century. Wheeler (1968) famously installed a ruling class in Indus cities by suggesting that its robust urban environment was evidence not of a prosperous, albeit relatively egalitarian, citizenry but instead the product of a homogenous and conservative military state-led by "priest-kings." This hypothesized hybrid of monarchy and theocracy was supposedly transplanted from Mesopotamia. As neo-evolutionary theories of social change arose in comparative archaeology during the 1960s, Indus scholars responded by focusing on whether or not the Indus civilization was a "state," the imagined endpoint of social evolution. However, proponents of the "stateless" (e.g., Possehl 1998) and "state-level" (e.g., Kenoyer 1994) paradigms suffered from the same thorny theoretical problems that have always accompanied the categorization of societies based on trait lists. It is telling that the $17.5-\mathrm{cm}$ statuette commonly called the "priest-king"one of the few pieces of evidence of their supposed existence-is now believed to be evidence of interaction with neighboring societies, not the talisman of a military elite (e.g., Vidale 2018a). In this article, I review the empirical evidence for a ruling class in the Indus civilization, finding that the traditional assumption that there was a simple correlation between complexity and hierarchy, and between simplicity and egalitarianism, can no longer be sustained.

\section{Do Complex Societies Necessarily Have a Ruling Class?}

In brief, no. Since the mid-20th century, archaeological attempts to explain the origins of complex societies were heavily indebted to evolutionary theories of social change based on historical or ethnographic research, which posited that societies progress through a series of universal stages that culminate in what are thought to be present-day social conditions (Trigger 1989).

These traditional theories of social complexity made two major claims: that all social trajectories converge on a common and universal evolutionary outcomethe "state," and that all states comprise more or less the same social phenomenanamely urbanism, political hierarchy, long-distance intercultural trade, and, importantly, political and economic stratification. The first claim has been thoroughly dismissed, but disentangling the agency of a ruling class from narratives of increasing social complexity is an ongoing project. While the presence or absence of a 
ruling class has rarely been addressed so directly, the strong tendency of scholars of complex societies to accept the role of a "ruling class," or coercive elites who directed past societies through disproportionate control of their wealth and power, deserves critical scrutiny.

Childe's (1950) widely cited article on the "urban revolution" was a touchstone for the study of social complexity. Childe sought to explain cross-cultural patterns in early excavation data from Egypt, Mesopotamia, and South Asia, famously offering a list of traits that he believed brought about a "revolutionary" process of urbanization. He mixed observable empirical phenomena, such as increases in settlement size, large buildings, and evidence of administrative technologies like writing, with theoretical assertions that were heavily influenced by Marx's speculations about what social relations were like in pre-capitalist societies. Among these theoretical assertions was the idea that the urban revolution was driven by a ruling class, who, through the state, exerted control of society by redistributing food surpluses. Childe's traits, as well as the pace of change thought to have characterized the urban revolution, have undergone considerable revision since the article's initial publication (e.g., Smith 2009); however, the core idea-that economic stratification and the emergence of a ruling class separate complex urban societies from those that predate them-has had a profound and continuing influence.

Childe's assumptions about a ruling class percolated into the substratum of archaeological thinking about complex societies. In early processual models, urbanization was used to explain the emergence stages of class relations by concentrating people and resources in space. This concentration is thought to have allowed an inchoate ruling class to reinforce its high status in society by employing specialists - artisans, soldiers and bureaucrats - to undertake various projects of legitimation and administration (e.g., Childe 1950; Flannery 1972; Service 1975; Trigger 1974; Wright 1977; Wright and Johnson 1975). Thus, we find a division between a ruling class who exercised power and subordinated classes who were subject to that power. Economic specialization, an observable pattern in archaeological data that was thought to result from the subordination of artisans, was thus closely associated with social complexity (e.g., Costin 1991; Eerkens and Bettinger 2001; Roux 2003; Schortman and Urban 2004). Artisans came to be conceptualized purely in terms of their attachment to a ruling class who managed the surplus food and materials necessary for craft production (e.g., Brumfiel and Earle 1989). In this way, Childe's "ruling class" was rebranded to the more generalized concept of "elites," who were defined by their high positions in a stratified social order. Elites and their artisans are thought to have tapped long-distance exchange networks to bring in exotic raw materials for specialists to transform into prestige goods that signify and cement their dominance over other social classes (e.g., Helms 1993).

Following the rise of elite-centered views of social complexity, there have been profound changes in the way archaeologists conceptualized the interrelationship between politics, hierarchy, production, and how the three come together in forms of early governance. Drawing on a cross-section of Mesoamerican complex societies, Blanton et al. (1996) argued that the different ways past elites could legitimize and reinforce their positions fall along a continuum between network 
strategies - those that involve creating alliances within exclusionary power networks - and corporate strategies - those that involve more subtle investments in public goods to minimize the perceived distinction between elites and the people over whom they exerted power. Corporate political strategies were often undertaken by decentralized and "egalitarian" political forms that were dis-embedded from exclusionary elite networks (Blanton 1998). Egalitarian in this sense was mainly political, associated with diffuse and distributed forms of power thought to accompany decentralized governance. Thus, where once archaeologists had imagined a relatively restricted cadre of ruling elites, there has been growing recognition of a vast range of varied political and economic strategies (Feinman 2011). Recognizing this political variability raised fundamental questions about how societies that lacked despotic ruling elites managed themselves.

The degree of "collective action" apparent in premodern societies is closely related to other characteristics of their political economies (Blanton and Fargher 2008). While the concept of collective action was originally borrowed from institutional economics (e.g., Olson 1965; Ostrom 2000), archaeologists have used the term to describe all forms of joint endeavor among people who share a particular resource. All societies exhibit some degree of collective action (otherwise we would not be able to recognize them as societies), but some societies appear to have been more willing to invest in collective endeavors that benefit broader society. The capacity for collective action has thus been recognized as a valuable variable for comparing complex societies, and it appears to be associated with other processes, such as the degree to which a society relies on bureaucracy (Blanton and Fargher 2016). Societies that fall on the collective end of this continuum tend to offer a greater range of public goods and make investments in open and accessible infrastructures. Collective societies also tend to take on more representative political institutions that divide power (Feinman and Carballo 2018), such as the republic identified at Tlaxcallan in prehispanic Mesoamerica (e.g., Fargher et al. 2011). This appears to be related to the fact that more collective societies rely on "internal" resources, such as taxes on agrarian surplus, as opposed to "external" resource such as exotic raw materials acquired through trade (Feinman 2018). There thus appears to be positive feedback between the growth of collective action and political representation and, importantly, inclusion. This makes sense, as the production of public goods, such as large-scale infrastructure or civil administrative systems that are accessible to a relatively wide cross-section of people, necessarily requires collective labor and thus produces more collective forms of governance, which in turn potentially include more diffuse and varied political organizations. While it is certainly conceivable that Childe's despotic ruling class could coerce society into collectivity, such a strategy would be at odds with the political inclusion that appears to be commensurate with collective action. This relationship between political inclusion and collective action may explain its occurrence in the absence of individual rulers, such as during the long period of neighborhood expansion at Teotihuacan in Mesoamerica (Cowgill 2015 , p. 190). To understand how the world's complex societies emerged, we must get beyond "elite-centered" and "exotics-fueled" models of social change (Chirikure 2020 , p. 141). Past societies clearly achieved remarkable feats of collective action in 
the absence of a ruling elite. How did these relatively egalitarian complex societies organize their collective action?

Such egalitarian complex societies would have to organize their collection action without recourse to a fixed and immutable hierarchy. Heterarchy, wherein social elements are either unranked or have the potential to be ranked in different ways (Crumley 1995), must therefore play a more important role in societies that lack a ruling class. While hierarchy has long been associated with social complexity, the often unexamined dynamics of heterarchy were often as essential to, or perhaps even the causal driver of, many social transformations (DeMarrais 2013; McIntosh 2005a). For example, the first states in Mesopotamia were the outcome of social and economic processes far removed from the establishment of political hierarchies (e.g., Algaze 2008; Porter 2012; Stein 1998; Ur 2010). Collective forms of social organization instead required a rigorous process of consensus building across large cross-sections of society. These processes of consensus making, and the cooperation it engenders, are what make collective action possible in the absence of a coercive political hierarchy (DeMarrais 2016; DeMarrais and Earle 2017; Feinman and Carballo 2018; Halperin 2017). Collective action may thus be more likely in contexts where people engage in a particular activity as a result of emergent decision making, such as we would expect in a society without a ruling class. Using cooperation and consensus to undertake collective action is very different from the network-based exclusionary strategies employed by a ruling class. While cooperation and consensus could potentially have involved a single group of elites, but there is no theoretical reason to assume this as a prerequisite.

If a ruling class is not a prerequisite for cooperation and consensus, it is reasonable to theorize that both can be achieved in relatively egalitarian political economic contexts. This is important because comparative studies indicate that an increasing capacity for collective action shapes long-term trajectories of social change in many parts of the world, so there must be a wide range of powerful social mechanisms for maintaining both cooperation and consensus (Carballo 2013). Certain forms of collectivity appear to mitigate the ability of leaders to engage in egregious acts of coercion and accumulation (Blanton and Fargher 2016; Feinman 2018; Feinman and Carballo 2018). This is likely to lead to the production of public goods and infrastructures that benefit society at large, creating a strong positive relationship between egalitarian social relations and collectivity. Might reproducing specifically egalitarian social relations be a powerful way of maintaining consensus and cooperation, in turn fostering increasing levels of collectivity?

Though archaeologists should not be shy about questioning the role of a ruling class in early complex societies, they have tended to be. It has long been unclear whether the economic differences apparent in early complex societies were analogous to divisions between the working and capitalist classes that Marx (1976) defined by their differing relations to the means of production in industrial economies. There has been considerable effort to study the origins of these classes (e.g., Wurst 1999), and to understand archaeology's role within capitalist class dynamics (e.g., McGuire and Walker 1999), but the deep history of class remains undertheorized. In response to Crone's (1989) claim that classes did not really exist prior to the industrial revolution, Trigger (2003, pp. 45-46) suggested that, in fact, a range 
of prehistoric classes are apparent in "stratified" societies, even defining "early civilization" as "...the earliest and simplest form of class-based society." In deep history, then, classes can be usefully considered stratified networks of corporate groups collectively defined by their economic status. And yet, archaeologists who compare early complex societies have been hesitant to argue that collective action and collectivity can emerge in the absence of elites.

What is left of Childe's trait list if we remove a stratified ruling class of managerial elites? Craft specialization appears in a very wide range of societies and is not universally associated with inequality (Clark 1990; Costin 1991; Costin and Wright 1998; Flad and Hruby 2008). It has been well established that markets and merchants appeared earlier than predicted by traditional models of social complexity (e.g., Algaze 2008; Broodbank 2013; Hirth and Pillsbury 2013). Far from being restricted to political economies rife with hierarchy and coercion, trade has commonly occurred in contexts where a ruling class is absent (Oka and Kusimba 2008). Indeed, even standardized systems of weights and measures, clear evidence of people attempting to develop commensurate quantities of goods, have been recovered in contexts that lack significant wealth differentiation (e.g., Rahmstorf 2019).

Can there be states in the absence of a ruling class? This is a thorny question, as even when neo-evolutionary models were at their height, the "state" was a contested concept. In archaeology, the early state has since undergone a long process of redefinition and revision, and archaic polities are now understood to take a range of political and economic forms far removed from what Childe imagined (e.g., Feinman and Marcus 1998; Pauketat 2007; Robb et al. 2013; Wengrow 2010; Yoffee 2005). While there are certainly examples of complex societies where despotic kings made bombastic claims to power and authority (e.g., Smith 2003), there are at least as many instances of early states that cycled through periods of centralization and disintegration (Lawrence and Wilkinson 2015; Stein 1998; Ur 2010), or where formal political hierarchies were fragile and unstable (Yoffee 2016, 2019). Many societies, moreover, tended to favor cooperative and representative forms of governance (e.g., Fargher et al. 2011; Feinman and Carballo 2018; Halperin 2017; Wright 2018). Understanding how different political and economic formations emerge and disintegrate is an ongoing project, but it would appear that political coercion carries with it a range of higher costs and may make social formations more prone to disintegration, while cooperation avoids some of those costs. A collective state based on cooperation may in fact require no coercion, and therefore lack a ruling class to do the coercing.

Cities easily survive the theoretical excision of a ruling class. This is one of the reasons that urbanization has become increasingly untethered from the social complexity trait list, and indeed there is a considerable literature surrounding its definition and characteristics (Cowgill 2004; Smith 2009, 2014; Wright 2002). Social complexity is relatively independent of population size and concentration (Feinman 2011). Instead, urbanization refers to the aggregation and concentration of large numbers of people and things within particular settings (e.g., Gyucha 2019; McIntosh 2005a, b; Smith 2014; Trigger 2003; Wright 2002). Jennings and Earle (2016) compared the archaeological records of the world's first cities and concluded that urbanization is only loosely associated with state formation and may have often occurred in direct resistance to efforts to build political hierarchies. Later cities 
certainly became entangled within large political projects, mainly at the behest of a ruling class seeking to take advantage of the economic growth stimulated by urbanization (e.g., Schortman and Urban 2011). Cities indeed appear to produce lots of things by concentrating people and resources, but they do so whether or not they also have a ruling class.

The relationship between a ruling class of managerial elites and wealth disparity could benefit from further research. It had been simplistically assumed that the concentration of power within a constrained ruling class would likewise lead to their acquiring a disproportionate share of wealth; however, archaeologists have found that social relations that increase the production of things often operate in ways that can be quite distinct from those that shape the flow of power. Wealth disparity can appear under social and economic conditions in which it should not, such as in the prehistoric Mediterranean's low-growth environments (Leppard 2019). Thus, not all kinds of inequality are the same, and it is worthwhile to evaluate the relationships between processes that lead to economic changes and those that create political hierarchies. Through careful attention to how different kinds of political and economic inequality relate to social relations and property, it has also become clear that specific social changes do not necessarily co-occur in monolithic and all-inclusive shifts into social complexity. Indeed, there are different kinds of elites that emerge at different times, such as billionaires, who appear long after the advent of cities. It is certainly true that urbanization can sharpen economic differences, but this does not appear to be a universal law.

This is all to say that archaeologists have honed an excellent set of theoretical tools for examining the processes that bring about a ruling class and separating these processes from those that bring about social complexity. Collectivity, specialized production, long-distance exchange, and urbanization have all occurred in different combinations in different societies, whether or not at the behest of a privileged cadre of managerial elites. And yet, the assumption that the political economy of complex societies will inevitably stratify remains firmly entrenched, even in settings where there is no empirical evidence for a separate group of rulers who are better off than everyone else. For example, a popular argument is that there is a causal link between urbanization, increasing agricultural labor demands, and wealth disparity (Bogaard et al. 2018, 2019; Fernández-Götz and Krausse 2017; Fochesato et al. 2019; Porčić 2019; Smith et al. 2018). Even in contexts where archaeologists are confident that power is diffuse and collectivity predominates, it is often assumed that wealth stratification lies behind large societal endeavors. Large-scale investments in labor are then used to infer the concentration of wealth in the hands of a ruling class, whether or not there is evidence for that class. This is doubly unfortunate, as the best lesson to be derived from collectivity in the archaeological record is that there appear to have been many different ways of governing complex societies.

It is therefore theoretically feasible for complex societies to lack a ruling class, so how should archaeologists go about identifying the presence of ruling class in the past? Given the prevalence of collective action in the archaeological record, we should be skeptical of a simple positive relationship between monumental architecture and social complexity (e.g., Smith 2009), a position that has been repeatedly strengthened by the discovery of labor-intensive monuments that predate cities, 
states, and ruling classes, such as the ritual center of Göbekli Tepe in Anatolia (e.g., Dietrich et al. 2012). Rather, large investments of labor only indicate the presence of a ruling class when they clearly benefit a restricted subset of people. Elaborate tombs, aggrandizing monuments, or large and restricted temples and palaces are the best evidence of a ruling class in the past (e.g., Pollock 1999). Such structures not only materialize the labor of the many but also clearly benefit the few (e.g., Hayden 1998; Trigger 2003).

Monumental tombs are therefore perhaps the best examples of evidence for the emergence of a ruling class. Each of the Old Dynasty Egyptian pyramids at Giza materializes the toil of thousands of individuals over decades to convey a single dead king to the afterlife (Wenke 2009, p. 297). These pyramids constitute large investments of the labor-and in some instances, lives - of many different people into structures that directly benefit only a single individual or their family. Retainer sacrifice is also strong evidence of a ruling class. The practice of killing and interring people upon the death of a ruler clearly reinforced the subordinate status of other classes-from specialists to commoners to prisoners (e.g., Campbell 2014; Morris 2014). Such sacrifices are seen in the Royal Tombs of Ur (Baadsgaard et al. 2011), which was constructed by the Indus civilization's contemporaries in Mesopotamia. When clear evidence of this sort is absent, evidence for craft specialization, long-distance exchange, and even relative wealth differences in residential contexts cannot serve as a substitute.

When their access was clearly restricted to a small subset of individuals, palaces and monumental temples also offer strong evidence of a ruling class. Each kind of structure restricts access to private spaces-protected places to interact with the divine in the case of a temple (e.g., Delougaz 1940) or the private domiciles of a privileged household in the case of a palace (e.g., Preziosi 1983). Clear facilities for craft production are sometimes attached to these structures, an indication that the occupants of a privileged place levied control over the labor of the specialists who worked in the attached facilities. Fewer indices of inequality are available outside of palaces or temples, and developing methods for quantifying economic inequality from broader settlement assemblages is a worthwhile endeavor. However, this goal has not yet been realized (Oka et al. 2018). Gini coefficients of the distribution of space among a sample of domestic structures have been offered as a cross-cultural measure of wealth inequality (Kohler et al. 2017; Kohler and Smith 2018). However, structure size alone is not a reliable measure of inequality because it is not always clear how many structures a corporate group owns and not all structures had the same social functions.

\section{The Forgotten Question of Indus Egalitarianism}

Whether or not Indus society had a ruling class has rarely been the explicit focus of debates about the political organization of the Indus civilization. The significance of the relatively equitable distribution of luxuries in Indus assemblages was lost in the mid-20th century argument that Indus cities were built by invaders, whose military regime was thought to have imposed a high degree of conformity, 
homogeneity, and conservatism on the people over whom they reigned (Piggott 1950; Wheeler 1953, 1968). This paradigm was popular until researchers began asking about the presence or absence and number and nature of Indus polities in the mid-20th century (Possehl 2002). There are now many different views about whether the Indus civilization was a cohesive polity, a collection of interacting polities, or even whether it shared a unified material culture at all (Agrawal 2007; Chakrabarti 2000; Chase et al 2014a; Cork 2011; Kenoyer 1997a; Petrie 2019; Possehl 1998; Ratnagar 1991; Shinde 2016; Wright 2010, 2018). However, many of these discussions are hampered by the trait-based social definitions researchers inherited from neo-evolutionary archaeology. While all of the current interpretations offer major improvements over the invader paradigm, Indus archaeology often suffers from theoretical assumptions about what should be present in a complex society, privileging these assumptions over actual evidence for what was present. This is particularly clear in the debate surrounding whether or not the Indus civilization was a "state." Here scholars have leaned most heavily on neoevolutionary trait lists, which they believed could be used to determine whether or not Indus society had achieved a particular evolutionary level. The Indus state debate involved numerous scholars, and a comprehensive review of each position is not possible here. Instead, I offer a summary based on two particularly wellknown positions within the debate.

Fairservis (1961, 1967) was an early proponent of the "stateless" paradigm, arguing that the Indus civilization was not a state based on an absence of political centralization and hierarchy. He contended that the Indus civilization was an amalgam of complex chiefdoms (Fairservis 1989). In response to critiques of neoevolutionism in the 1990s, Possehl (1998) updated and reiterated Fairservis' argument, reasoning that because the Indus civilization lacked clear evidence of a political hierarchy, it should not be classified as a state, even if its large populations, cities, and sophisticated architecture undoubtedly made it a "complex society." The lack of a particular trait-in this case elites and sharp political hierarchies-justified the omission of the Indus civilization from the neo-evolutionary "state" category, implying adherence to the idea of progression through a sequence of social types but excluding the Indus civilization from the highest evolutionary category. Emphasizing categorization obscured important considerations of social process that were evident in specific patterns in the archaeological data.

The stateless argument prompted a strong reaction, which I call the "state-level" paradigm. Kenoyer (1994, p. 76) advocated the state-level position, critiquing the "stateless" paradigm's reliance on trait lists developed in other social contexts but suggesting that a lack of evidence for a ruling class in the Indus civilization was the result of vagaries in archaeological excavation and recording, not the actual absence of a ruling class. In his view, the presence of craft specialization was enough to place the Indus civilization into the state category and to infer stratification without direct evidence, a position that was foreshadowed in a growing body of work on craft production at Mohenjo-daro (e.g., Vidale 1989). By inferring a ruling class from evidence of craft specialization, adherents of the state-level paradigm implicitly adopted the same static, neo-evolutionary trait list, substituting what would be considered clear evidence of a ruling class in other parts of the world-palaces, 
tombs, and aggrandizing individuals - for sophisticated craft technologies and extensive interaction networks.

By the late 1990s, the concept of heterarchy had been adopted by Indus archaeologists in both the stateless and state-level paradigms to explain patterns in Indus city planning and the high number of social groups involved in Indus craft production (Kenoyer 2006; Possehl 2002). In both paradigms, Indus political organization emerged through the heterarchical interaction of many different social groups. It remains unclear how heterarchy impacted other aspects of social organization, such as the distribution of wealth, or to what extent Indus heterarchy formed an alternative to hierarchy. Still, it is now widely argued that multiple groups contributed to the construction of Indus cities and the economic activities undertaken within them, and none seemed to dominate the others (e.g., Petrie 2013a, b, 2019; Vidale 2010, 2018b; Wright 2010, 2018). This is, of course, true of most cities, which are rarely controlled by a sole centralized authority. However, again, it is important to address the relationship between heterarchy and the presence or absence of a ruling class. While it is often counterposed to hierarchy, heterarchy is found in otherwise extremely unequal societies (Brumfiel 1995), characterizing the elite interactions between powerful political hierarchies in early medieval Ireland (Wailes 1995) or competition between imperial elites in different parts of the Roman Empire (Tainter and Crumley 2007). A comprehensive consideration of the relationship between heterarchy and governance is beyond the scope of this paper, but I do not think there is sufficient evidence to support the view that a ruling class of managerial elitesheterarchical or otherwise-directed the political organization of Indus society.

In this review, I focus on the kinds of evidence of inequality that would be sufficient to identify a ruling class from a comparative perspective. To avoid assumptions about stratification, I conceptualize social units in the Indus civilization without assuming they were stratified into different political and economic classes. The anthropological term, "corporate group," is thus an appropriate concept for thinking about Indus political organization. A corporate group is made of up people who enjoy shared access to common property (e.g., Goodenough 1978; Hayden and Cannon 1982; McIntosh 2005a). All societies include different kinds of corporate groups-quintessentially households but also palaces, temples, guilds, governments, militaries, and other kinds of associations. The degree to which corporate groups restrict production and have uneven access to wealth is what determines whether they differentiate into classes, wherein a particular corporate group monopolizes a specific relationship to the means of production that places its members in a different stratum than other corporate groups.

\section{Trajectories of Indus Urbanization}

The Indus civilization emerged across a larger area than many other early complex societies, and its substantial geographical extent is considered one of its defining characteristics (Kenoyer 1997a; Petrie 2013a, b; Possehl 2002; Shinde 2016; Sinopoli 2015; Wright 2010, 2018). Differences in environment and material culture divide the Indus civilization into five regions: northwest India, the Upper Indus 


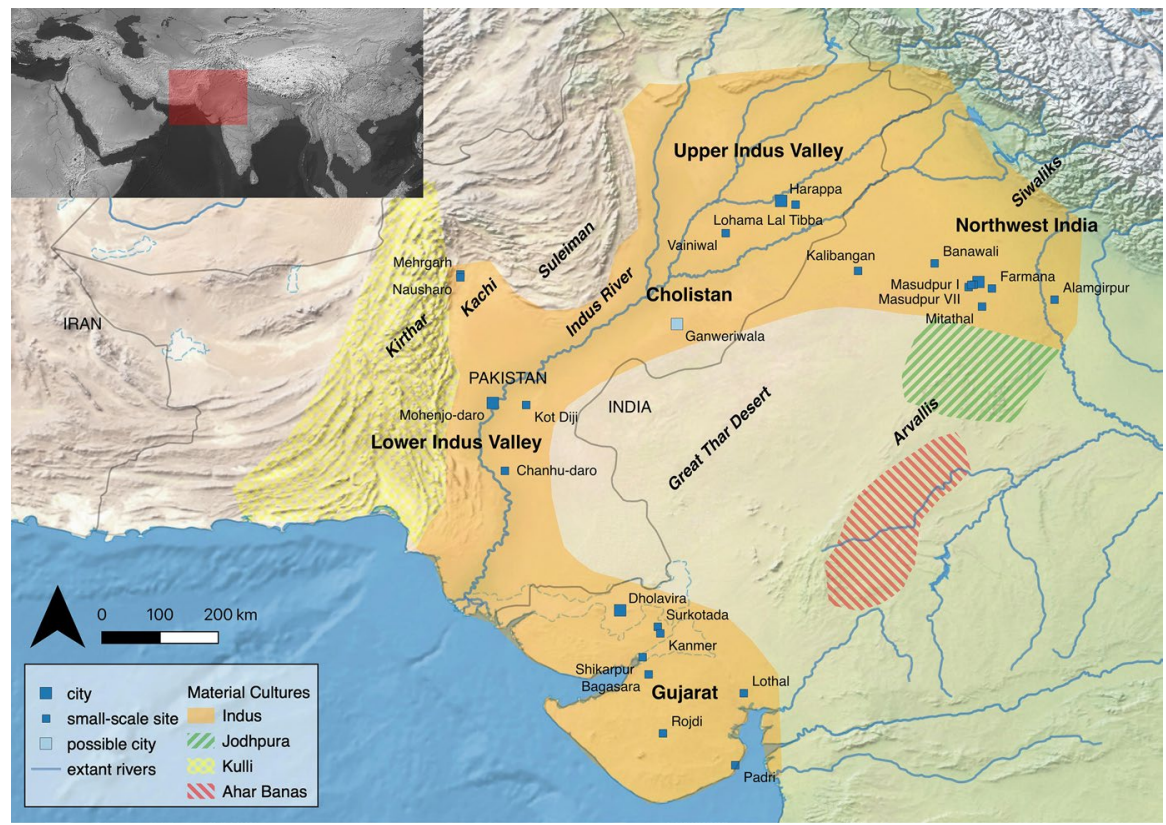

Fig. 1 Map of the Indus civilization and some contemporary neighboring material cultures. Five main regions are highlighted, as are the size and location of sites discussed in the text. Data are projected in WSG 1984 on version 4.0 of the Natural Earth Basemap using QGIS 3.10

Valley, Cholistan, the Lower Indus Valley, and Gujarat (Chakrabarti 2009; Kenoyer 1997a; Possehl 1999; Sinopoli 2015; Wright 2010) (Fig. 1). By around 3300 BC, people in each region began building permanent settlements-each maximally around 10 ha-that had large architectural features, such as rectilinear mud-brick architecture and mud-brick walls surrounding a portion or the entirety of the settlement (Fig. 2) (e.g., Ajithprasad 2002; Ajithprasad and Sonawane 2011; Bisht 2015; Joshi et al. 1984; Lal 2003; Possehl 1999; Rajesh et al. 2013). At Kalibangan, for example, thick walls enclosed a complex of smaller "houses" that were arranged in neat rectilinear blocks (Lal 2003). Kot Diji's early plan includes a major wall that separated two clusters of smaller houses that do not differ significantly in size or available amenities (Khan 1965). Similar patterns are reported from Harappa (Kenoyer 2008; Wright 2010), Dholavira (Bisht 2015), Farmana (Shinde et al. 2011), Rehman Dheri (Durrani et al. 1991), and Surkotada (Joshi 1990). Despite evidence of large-scale construction-a significant form of collective action-none of these structures appear to have had features associated with a particular corporate group. Indus egalitarianism thus originated long before Indus settlements became cities.

There are different views regarding what prompted the growth of Indus cities around 2600 BC. Some have argued that the urbanization process was propelled by migrations from urban centers into different parts of the Indus zone (e.g., Possehl 1999). More common is the view that the Indus civilization emerged through multiregional interaction (e.g., Agrawal 2007; Chase et al. 2014a; Kenoyer 1998; Shaffer 


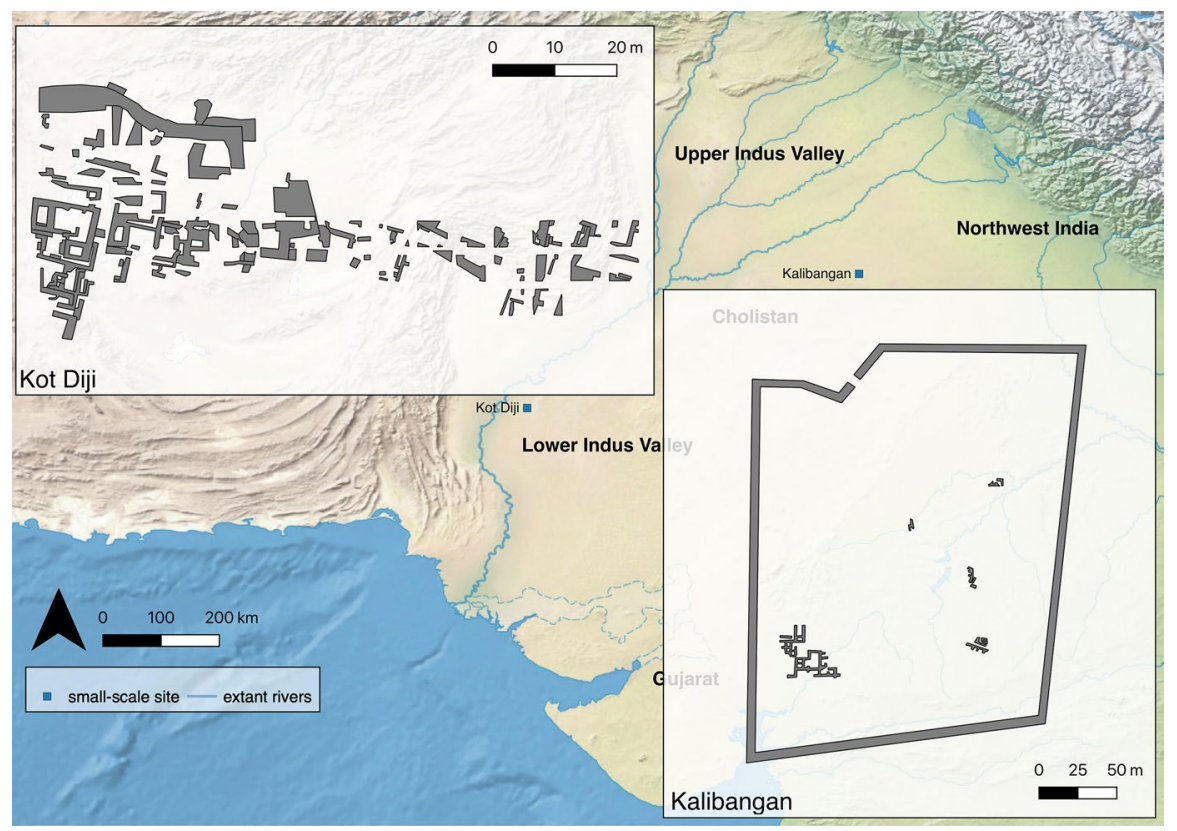

Fig. 2 Large-scale architecture from the pre-Urban phase. Plans derived from Khan (1965) and Lal (2003) and added as insets to a basemap derived from Figure 1

1992; Shinde 2016; Shirvalkar 2013; Wright 2010). This latter view would make sense if the Indus civilization grew through consensus and cooperation, and not military expansion. Only five sites-Harappa, Rakhigarhi, Mohenjo-daro, Ganweriwala, and Dholavira, one in each region-are typically identified as cities. Many of the hundreds of other reported Indus sites are, in fact, smaller than 30 ha (e.g., Fairservis 1989). As a result, there has been a concerted effort to integrate these "satellite" or "rural" settlements into theories of Indus urbanization, with some scholars identifying patterns of specialization at small settlements (Wright 2010, p. 143) and others suggesting that small settlements materialized the "rural complexity" of Indus civilization (Parikh and Petrie 2019).

\section{Food Production}

Agriculture is often considered an engine of inequality because cultivating crops can require a great deal of labor. However, there is no strong evidence that Indus food production required a subordinated class of farmers, and, indeed, the high number of small settlements suggests that most of the Indus population was indeed somehow involved in food production. Indus agriculture seems to have increased the range of specialized plants and animals that settlements had access to, while Indus farmers grew cereals, vegetables, larger fruits, and fiber crops (Bates 2019a, b; Fuller 2006; Petrie and Bates 2017; Weber 1999; Wright 2010). Sites in the Indus 
River basin appear to have been more closely associated with wheat/barley production (Weber 2003), and sites in northwest India appear to have relied on different combinations of winter and summer crops (Petrie et al. 2016; Petrie and Bates 2017). Different combinations of summer crops-namely millets and rice-were used to complement winter staples like wheat and barley (García-Granero et al. 2016; Pokharia et al. 2014; Singh et al. 2012; Weber 1991; Weber and Kashyap 2016). Many Indus cropping strategies were locally adapted (Petrie 2019; Petrie et al. 2017), and settlement distribution data indicate that it may have been easier to transport items from the city to the rural settlements in northwest India than vice versa: Rakhigarhi may not have been fed by rural surpluses produced outside the city (Green and Petrie n.d.). The diversity and flexibility of their agricultural practices indicates that Indus farmers were not likely trapped in subordinated tributary relations with a ruling class.

Domesticated animals were used in the production of primary products-meat, hide, and bone-and secondary products such as traction (Miller 2003), which suggests that animals were involved in processes of economic intensification and specialization based on animal husbandry practices already in place (e.g., Sherratt 1981). Dairying may have increased with the development of cities, though the lipid analysis of cooking pots indicates that most vessels were used in the production of an array of different animal products (Suryanarayan 2019). Cattle, buffalo, sheep, goats, and pigs have all been identified in Indus assemblages (Channarayapatna 2018; Chase 2010; Meadow 1998; Meadow and Patel 2003), which also include wild animal species-muntjac, blackbuck, and even elephant-that were presumably hunted. Isotopic data from faunal remains indicate that these species were managed in different ways (Chase et al. 2014b; Lightfoot et al. 2020). Fish appear to have been preserved and transported to Harappa, some of which were obtained from coastal zones (Belcher 2003). The urban economy of the Indus civilization thus incorporated a wide array of animal specialists, pastoralists and hunters alike.

Indus communities used a range of plants to produce such textiles as cotton and jute (Wright 2010), and animal products such as wool (Meadow and Patel 2003) and silk (Good et al. 2009). These textiles are strong indicators of specialized production because they often combine the labor of many different producers and generate larger quantities of goods than can easily be consumed by the members of a production unit. Wool was a core product of specialized pastoral economies in the early civilizations of southern Mesopotamia, agglomerating specialist labor to generate an exportable commodity that formed a link to settlements far from urban centers (Algaze 2008; McCorriston 1997; Wilkinson 2014). Perhaps the best indication of such specialization may have been water buffalo pastoralism, which is evident in the faunal assemblage of Dholavira (Patel et al. 1997), as a single animal tends to produce far more milk than would have been required by an individual family.

\section{Settlement Growth and Nucleation}

Beginning around 2600 BC, Harappa, Mohenjo-daro, Dholavira, and Rakhigarhi grew into cities (Figs. 3, 4 and 5). The same may be true of Ganweriwala, though 


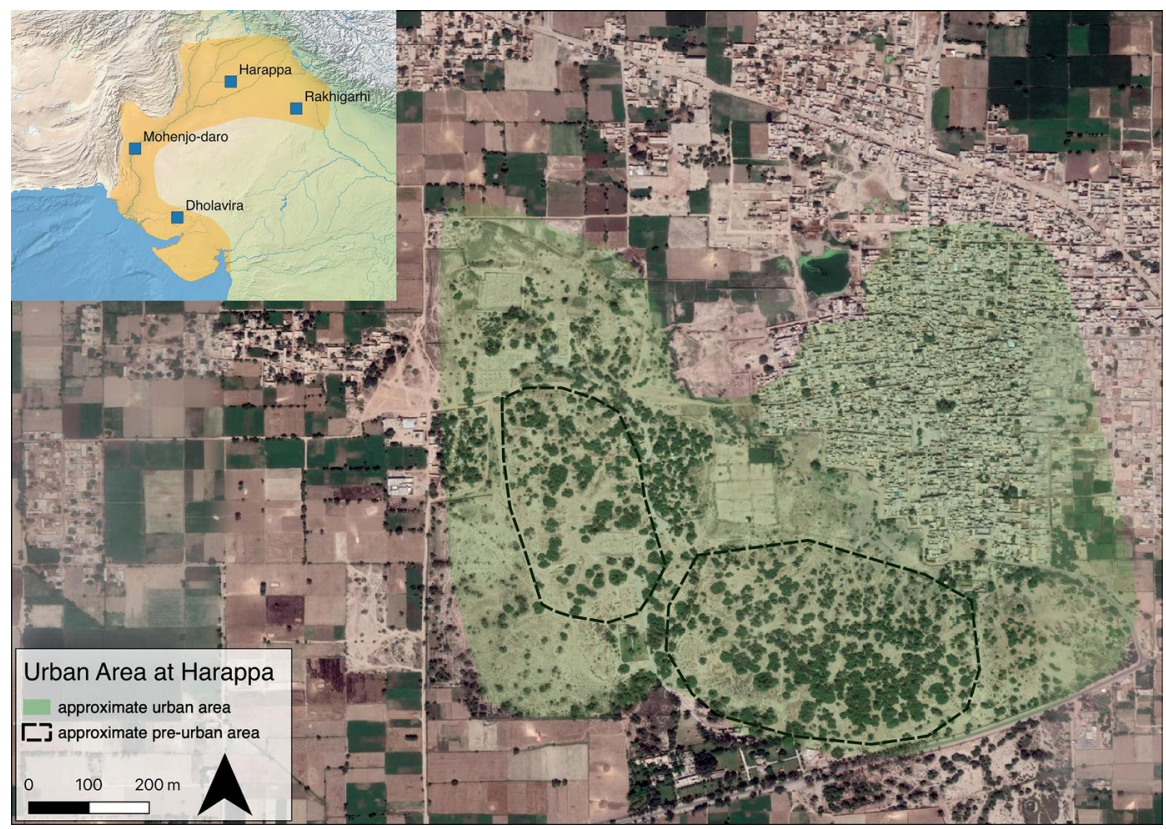

Fig. 3 Settlement growth evident at the Urban phase site of Harappa (Meadow and Kenoyer 2005). Extent polygons generated from site plans using QGIS 3.10 and then added as insets with Google Earth imagery (accessed 2020) to a basemap derived from Figure 1

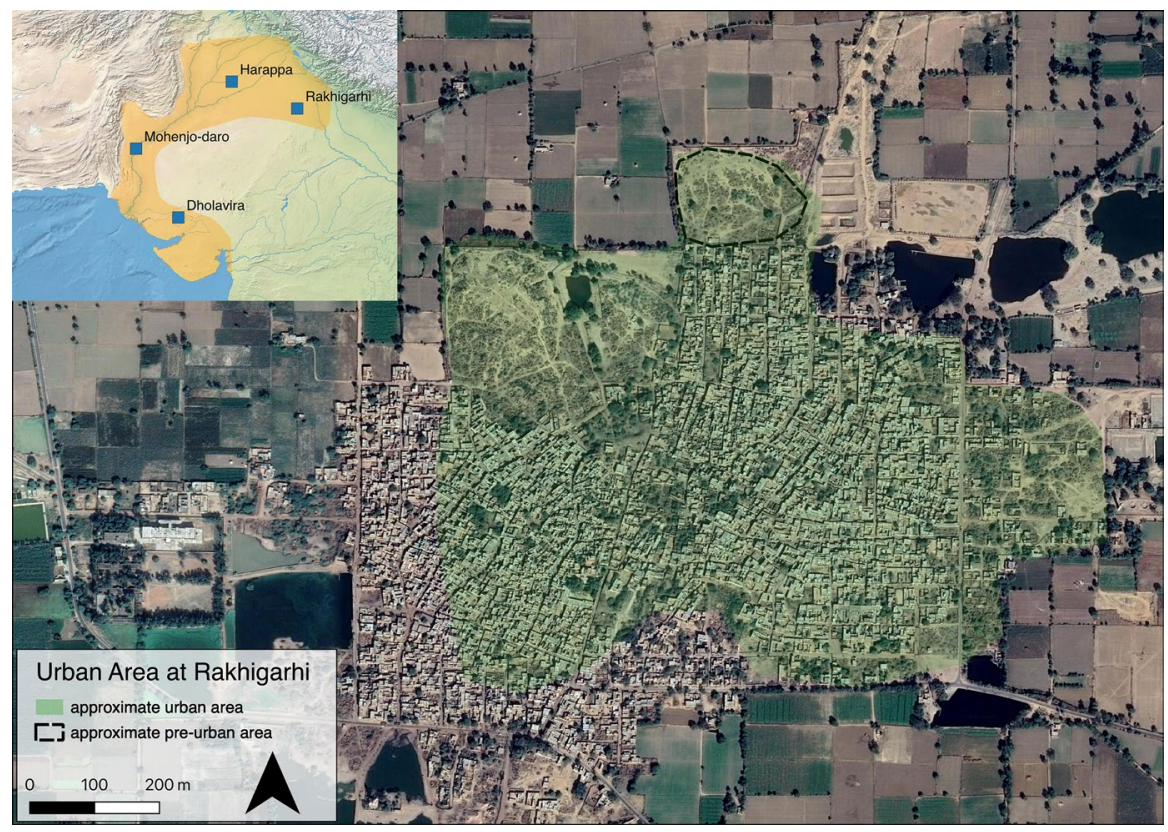

Fig. 4 Settlement growth evident at the Urban phase site of Rakhigarhi (Nath 1998, 1999, 2001). Extent polygons generated from site plans using QGIS 3.10 and then added as insets with Google Earth imagery (accessed 2020) to a basemap derived from Figure 1 


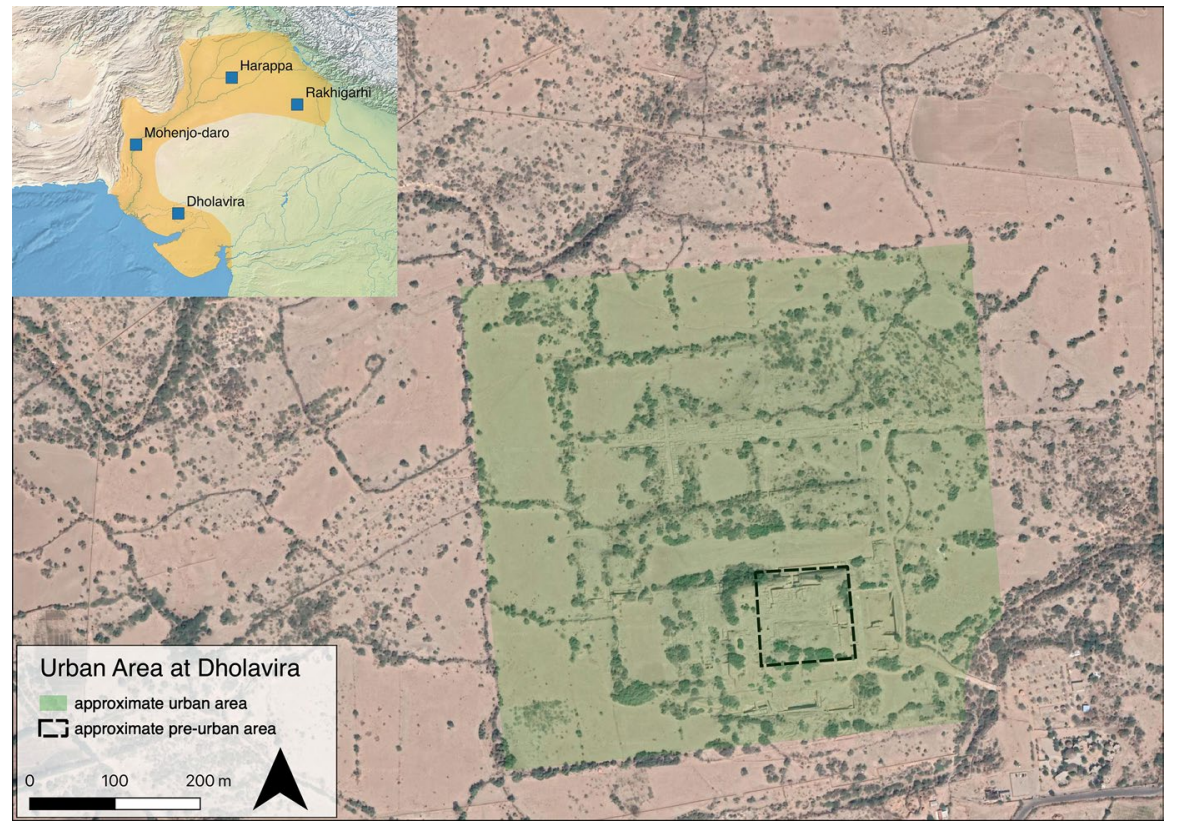

Fig. 5 Settlement growth evident at the Urban phase site of Dholavira (Bisht 2015). Extent polygons generated from site plans using QGIS 3.10 and then added as insets with Google Earth imagery (accessed 2020) to a basemap derived from Figure 1

only survey data are available (e.g., Masih 2018; Mughal 1997), and there are multiple sites in the surrounding area that appear to be equally extensive (e.g., Orengo et al. 2020). Harappa's elevated mounds were established at different points in time but were all occupied beginning around 2600 BC (Kenoyer 2008; Meadow and Kenoyer 1997, 2005; Wright 2010). At the same time, new construction activities at Rakhigarhi appear to have elevated mounds adjacent to existing structures (Nath 1998, 1999, 2001; Shinde et al. 2012). Dholavira underwent a period of building expansion, but the site's inhabitants did not separate their structures into mounds. Rather, at Dholavira walled segments were built around the earliest occupied area, increasing the site's overall size (Bisht 2015). Substantial new building projects were thus undertaken at all three sites, each of which grew to encompass a greater area than was occupied during the pre-Urban phase (ca. 3300-2600 BC).

Mohenjo-daro's pattern of building expansion is less well understood. There is scant evidence for a settlement preceding urbanization (Dales et al. 1986; Jansen 1994), so it has been argued that Mohenjo-daro's growth was the sudden expression of a new and nihilistic ideology (Possehl 2002, p. 55). This seems unlikely, as all of the other excavated Indus cities overlay older settlements. Mohenjo-daro's structures appear to have been constructed over interlocking foundation platforms that conformed to planned streets, private lanes, and a system of water drainage infrastructure (Jansen 1993, p. 269). Such platforms supported Mohenjo-daro's large-scale nonresidential structures, and other platforms supported blocks of houses that were 
divided into neighborhoods (Jansen 1978, 1994, 1984b; Mosher 2017). It is unlikely that there was no preceding settlement, and large-scale nonresidential structures also were found at Harappa and Dholavira, but the sheer intensity of building evident at Mohenjo-daro may well have exceeded other Indus cities.

The majority of Mohenjo-daro's structures were small and included a number of apparent multipurpose rooms surrounding courtyards that included hearths (e.g., Kenoyer 2012). Such building plans are consistent with what many archaeologists and anthropologists would define cross-culturally as houses/residences of indivisible kinship units (e.g., Blanton 1994; Netting 1993). It is telling that Mohenjo-daro's first excavation report did not begin with exaltations of royal wealth and power. Instead, it began by presenting the plan of House VIII in the HR Area, a multistoried brick building consisting of a dozen rooms arrayed around a compact central courtyard (Marshall 1931). Its entrance was tucked away on a narrow lane that ran into a wider street, and its thick walls supported neighboring houses. At its height, Mohenjo-daro was thus a city of well-built rectilinear houses aligned with major streets (Fig. 6).

Mohenjo-daro's houses were varied and densely interconnected, which complicates efforts to differentiate individual structure plans. As a result, it has often been argued that they were relatively uniform. Chakrabarti (2014, p. 114) argued that attempts to identify different kinds of structures among the houses are "nothing but excavators' attempts to infuse some character into the vast piles of burnt-bricks." I think that this pervasive view-which is closely related to Wheeler's argument

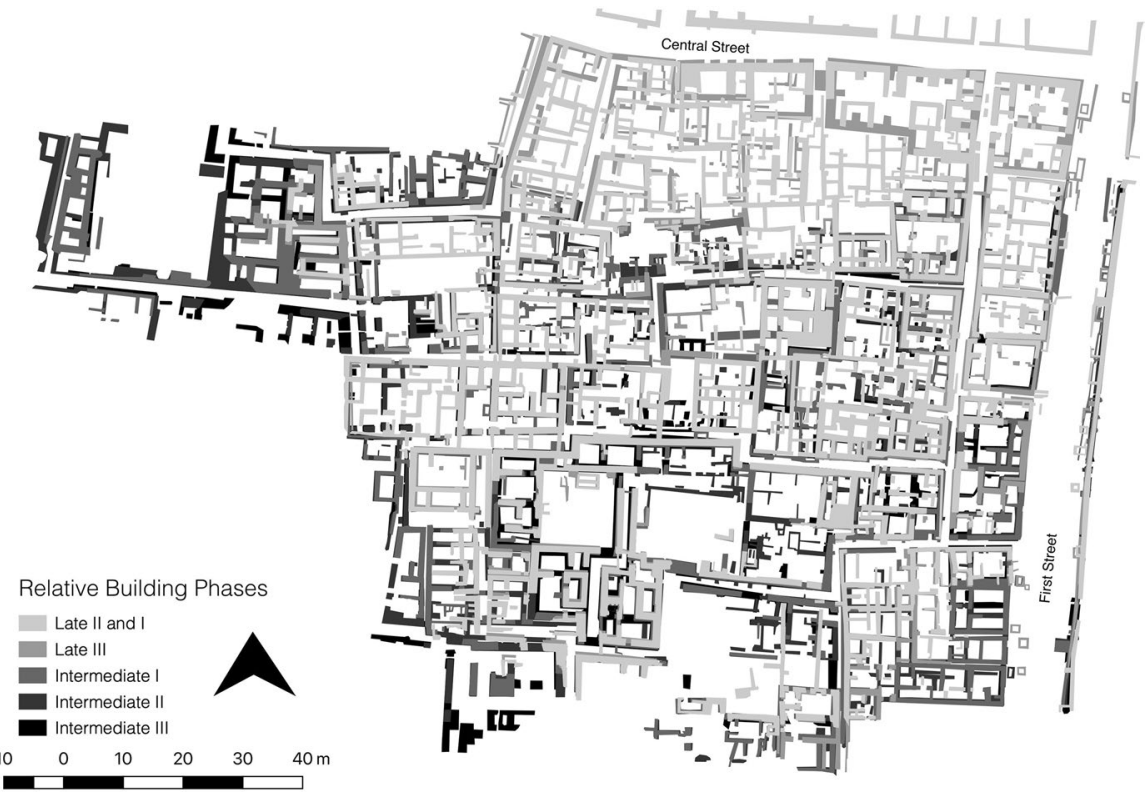

Fig. 6 Relative building chronology evident in Area DK-G of Mohenjo-daro. Earlier phases are darker; later phases are lighter. Note the significant expansion of small-scale houses conforming to the city's street plan. Figure derived from the analysis carried out in Green (2018) and assembled using QGIS 3.10 
that Indus material culture was uniform and conservative-derives from the overwhelming amount of rich architectural data archaeologists uncovered when they excavated at Mohenjo-daro, which resulted in a legacy dataset with which archaeologists are only starting to come to terms. Entire blocks from the initial excavations at Mohenjo-daro remained completely unpublished until a revisitation project in the 1980s (Jansen 1984b). Investigations of these data reveal plenty of "character" in Mohenjo-daro's structures. There were different kinds of structures distributed throughout the site, such as a pair of small nonresidential structures that I have argued served public purposes (Green 2018). Houses came in a variety of different types, all of which incorporated courtyards, wells, and specialized domestic activity areas (Sarcina 1979). Cork (2011) argued that this heterogeneity is evidence that the range of house plans in the Indus civilization was more similar to contemporary Mesopotamia than is typically acknowledged. Vidale (2010) even called a number of Mohenjo-daro's larger houses "palaces," suggesting that they were used by different groups of elites and noting that some may have included smaller "baths" that are similar to the nonresidential structures of the western mound. It is certainly true that some houses were relatively larger than others, but there is no evidence that any of Mohenjo-daro's houses served as a singular seat of authority that combined polity administration with the domestic activities of a ruling kinship group. Moreover, most of Mohenjo-daro's houses were similarly commodious and well appointed. The very largest of these were simply houses of above-average size; at best mansions, but not palaces analogous to those occupied by the ruling class in other complex societies (e.g., Trigger 2003, p. 565). Access to a few more rooms does not make you a priest-king.

Mohenjo-daro's smaller houses appear to have been temporally restricted to the later phases of the site's occupation, with structure size generally decreasing though time and later structures tending to have thinner walls (Wilkins 2005). In Area DK-G, the larger houses are actually the earliest structures at the site, and not necessarily contemporary with the numerous smaller houses constructed over the course of the city's occupation (Green 2018). The total area of the site's nonresidential structures is small in comparison with the numerous rectilinear structures that flank hearth-equipped courtyards. Mohenjo-daro's houses were arranged in rectilinear blocks and shared an intricate system of drainage pipes that allowed each structure to have a private bathing platform (Jansen 1989, 1993).

This drainage system was a considerable feat of collective action, serving the majority of Mohenjo-daro's residences and revealing cooperation among many different urban groups (Wright 2010, pp. 124, 242). The household bathing platforms it facilitated may indicate the emergence of new forms of subjectivity (Rizvi 2011). These new subjectivities, inferred differences in household status based on marginally better position in the drainage system, and the substantial labor required to operate the draining system have all been cited as possible evidence for social hierarchies (Rizvi 2011; Wright 2010, p. 242; Wright and Garrett 2018). Maintaining these systems could have been unpleasant work, but there are examples of unpleasant work in all societies, egalitarian and otherwise, and there are numerous strategies-scheduling, task rotation, and lotteries to name a few-for distributing unpleasant work that do not entail a ruling class. Moreover, it is telling that the city was defined not by a 
royal district or tomb but instead by the relative comfort and privacy that appears to have been widely available.

Mohenjo-daro's houses were separated into "neighborhoods," blocks of structures that grew at different rates and according to their own internal logics (Jansen 1994). A similar pattern of neighborhood differentiation has been identified at Harappa, where multiple neighborhoods were separated by walls, gateways, ramps, and guardrooms (Wright 2010, p. 125). The structural differentiation between neighborhoods suggests that the social groups who built them were politically independent (Kenoyer 2006, 2008, 2012; Wright 2010, 2016, 2018). Indus cities may thus have been polycentric, growing as an aggregate result of interactions between multiple centers of power (Petrie 2013a, b).

The vast majority of Indus settlements were not cities (Petrie 2013a, b; Sinopoli 2015; Wright 2010). However, with Indus urbanization, many of these smaller settlements, such as Farmana (Shinde et al. 2011), Banawali (Bisht 1987), Kalibangan (Lal et al. 2015), Surkotada (Joshi 1990), and Shikarpur (Bhan and Ajithprasad 2012), also expanded and transformed. They exhibit similar evidence of urbanization as the cities, such as specialized goods and planned streets, which appear in the small-scale settlements of Vainiwal and Lahoma Lal Tibba (Wright et al. 2003, 2005). At Kalibangan (Lal et al. 2015), a "lower town" four times the size of the preceding settlement appeared to the east. People at many of these small-scale settlements also engaged in specialized production activities (Wright 2010, pp. 130-133). At Chanhu-daro, a massive pyrotechnical facility appears to have been involved in bead production (Mackay 1943; Sher and Vidale 1985). Mitathal had numerous faience production features (Suraj Bhan 1975; Uesugi et al. 2013). Khanak has crucibles and pyrotechnical features, and was almost certainly involved in the production of copper artifacts (Singh et al. 2015). Lothal's Urban phase occupation included a possible dock or reservoir and "warehouse" (Rao 1973). Kanmer (Kharakwal 2012), Bagasara (Bhan et al. 2004), and Nageshwar (Hegde et al. 1990) have craft activity areas that were enclosed by thick stone walls. The small site of Padri specialized in salt production (Shinde 1992). The increase in small settlements in Gujarat coincided with the consumption of an increased range of meats and seafoods (Chase 2010) and distinctive patterns of pastoral land use (Chase et al. 2018).

In most areas, Indus site distribution data reveal a trend toward reduction in the overall number of settlements during the Urban phase (ca. 2600-1900 BC). In Cholistan, there appears to have been an increase in settlement numbers and in settled area (Mughal 1997; Petrie and Lynam 2020), and in northwest India, archaeological surveys have revealed a significant reduction in the number of settlements surrounding Rakhigarhi (Green and Petrie 2018; Green et al. 2019; Singh et al. 2010). The concurrent growth of urban settlement area suggests that a subset of older settlements may have absorbed population from others that were abandoned in close proximity. Urbanization reconfigured social relations between existing communities; it does not appear to have been the automatic outcome of population growth, a pattern apparent in the growth dynamics of other early complex societies (e.g., Feinman 2013). 


\section{Craft Specialization and Exchange}

Abundant debris from the production of beads, bangles, weights, seals and sealings, and tools have been recovered throughout the Indus civilization. These artifacts form the core datasets for a strong tradition of Indus technology research (Kenoyer 1997b; Miller 2007; Rizvi 2015, 2018; Vidale 1989, 2000; Wright 1991). For example, investigations of the surface assemblages of Mohenjo-daro's mounds revealed significant quantities of craft debris (e.g., Pracchia et al. 1985; Vidale 1986; Vidale and Balista 1988). Most craft activities occurred within the houses of Mohenjo-daro's eastern mounds, where different crafts were comingled (Vidale 2000). A considerable amount of production thus appears to have occurred within houses. Unpublished field books from the initial excavations at Mohenjo-daro reveal that House VIII was no exception (Jansen 1984a). Ceramic production at Harappa also appears to have been located in different houses and not centrally administered (Wright 1991). There was no "industrial quarter" at the site of Harappa (Miller 2000, p. 96).

This intermingling of craft debris at many different locations across sites suggests that many different corporate groups were involved in production. Indus craft production is also thought to have incorporated large pools of craftspeople to generate substantial output (Menon 2008). Artisans who worked in different crafts worked alongside one another and shared their knowledge. Craft activity areas appear to have been organized according to the production techniques they employed. At Harappa, reductive craft activities, such as those used in stone bead production and flint knapping, were separated from transformative crafts like ceramic production and metallurgy (Miller 2007, p. 41). Crafts that incorporated both kinds of processes tended to be found in both localities. Artisans working on different crafts may have found themselves in close proximity with one another, spurring the exchange of knowledge and technological innovation (Miller 2000, p. 99, 2007, p. 43).

Indus crafts typically incorporated complex production sequences of action that required specialized knowledge and many different steps (Kenoyer 1992; Vidale 2000; Wright 1991). Common technological styles—-shared ideologies, and beliefs or cosmologies-permeated the sequences used to produce multiple crafts (Wright 1993, p. 243). One such style has been described as "technological virtuosity," the substantial investment of energy and knowledge into the production of small portable objects (Vidale and Miller 2000). Examples of virtuosity include stoneware bangles-sintered terracotta bangles that were fired in highly controlled environments with the assistance of clay saggars (Vidale 1990, 2000; Wright 2010) —and "etched" carnelian beads that required multiple cycles of heating and chemical treatment (Kenoyer 1996; Kenoyer et al. 1994; Roux 1999).

The materials used in craft production also offer insights into the construction of wealth and value in the Indus. Raw materials for certain craft goods circulated across long distances within the Indus civilization (Lahiri 1990). Law (2011) found that many of Harappa's semiprecious stones, such as the agate used to produce etched carnelian beads that came from sources far from the city in Gujarat, originated hundreds of kilometers away. Indus artisans favored dolomitic steatite that could be whitened, which appears to have come from a limited number of specific sources located in the mountainous regions in Hazara, north of the Indus 
civilization's extent (Law 2011). Such dolomitic steatite appears to have been the main ingredient of the Indus civilization's "talc-faience industrial complex," which included a range of crafts that incorporated materials that could be transformed (Miller 2008b). Kenoyer (1992) suggested that the level of technological knowledge needed to produce a particular craft was evidence for value hierarchies in the Indus, a view that was elaborated in subsequent studies (e.g., Miller 2008a; Vidale and Miller 2000). Indus communities highly valued objects made of artificial materials, such as faience and stoneware bangles, even more so than those that were made of exotic materials acquired over great distances (Miller 2008b; Wright 2010). Shell bangles were most often carved using mollusk species from coastal Gujarat (Dales and Kenoyer 1977; Kenoyer 1984; Sonawane 2018). Chert from the Rohri Hills in the Lower Indus Valley was preferred to locally available sources (Law 2011); however, additional sources in Sindh may also have been utilized (Biagi et al. 2018).

Kenoyer (1997b, 2000) has argued that particular groups constrained control of raw materials to attain a higher position in Indus society. The third millennium BC was certainly a period of long-distance intercultural interaction (Aruz 2003; Broodbank 2013; Laursen and Steinkeller 2017; Pittman 2013; Wright 2010), and Indus seals and beads have been recovered from numerous excavations in Arabia, Iran, and Mesopotamia. A great deal of Indus material culture, particularly ceramics, has been identified at coastal sites in Oman and on Bahrain (e.g., Frenez 2018b; Laursen 2010). Indeed, most of the Indus artifacts that have been recovered from non-Indus assemblages are small and portable-beads, seals, and images. There is, however, no evidence that a particular group of Indus producers was excluded from the use of materials attained through this long-distance interaction. The favored materials for hallmark Indus crafts, such as carnelian and steatite, have been recovered from most Indus settlements, often in significant quantities. This is particularly true within sites, where there is little evidence that craft activities or the products that were created were spatially restricted.

People living in small settlements enjoyed many of the same crafts that were evenly distributed within the cities. Goods made from steatite, faience, carnelian, and gold have also been recovered from small settlements in northwest India (Parikh and Petrie 2019). Agate beads and shell bangles are present in larger proportions at sites in Gujarat, suggesting that some settlements had better access to these goods, but these settlements are also proximal to the most utilized sources of these stones, reflecting perhaps the cost of transportation. While stoneware bangles were relatively rare in comparison to other artifact categories, they were not confined to the houses of "wealthy" individuals. Even if stoneware bangles were restricted to a particular community, we would still be talking about a form of inequality fundamentally different than the class boundaries that result in pyramids and retainer sacrifice in other complex societies. Different Indus communities may have preferred certain materials, but there is no reason to infer that these preferences were fueled by the tastes of a ruling class. It is more reasonable to propose that different materials were used solely in expressing horizontal differences between different groups.

Stoneware bangles, etched carnelian beads, and stamp seals are often cited as examples of Indus wealth (Kenoyer 2000). Yet these goods appear to have been widely available to urban populations and not restricted to a ruling class. The whole 
point of the talc-faience industrial complex, Miller (2008a, p. 145) argues, is to produce large quantities of highly valued artificial goods for broad distribution. Steatite microbeads, made in the thousands, required an extended production sequence that involved reducing steatite to a paste, forming it into blanks, firing it at high temperatures, and then slicing it into hundreds of tiny bright white ornaments, which were found in huge quantities at many Indus sites (Miller 2008a). The goal this increased production must have been to serve a large population, perhaps to distribute valuable objects to all urban consumers. In support of this point, many of the most sophisticated Indus craft goods are found relatively evenly distributed throughout Indus settlements. Metal hoards are distributed across Indus sites, and many Indus burials contain nearly identical quantities of grave goods (Rissman 1988). Stoneware bangles and stamp seals, argued to be the most highly valued of Indus craft goods, are found in many different contexts at both Mohenjo-daro and Harappa.

Stamp seals engraved with imagery and inscribed with text are among the defining crafts of the Urban phase. Although they were made of a range of materials and a variety of shapes, the typical Indus seal was carved from steatite, cuboid in shape, and engraved on a square obverse face (Mackay 1931). Such seals have been recovered in large quantities throughout the Indus civilization, 2500 seals from Mohenjo-daro alone (Joshi and Parpola 1987; Parpola et al. 2010; Shah and Parpola 1991). They are without a doubt examples of technical virtuosity; after they were cut from raw steatite and engraved with intricate images, they underwent surface treatment that involved heating them to over $120{ }^{\circ} \mathrm{C}$ (Kenoyer 2010; Law 2003; Vidale 1986). Indus seal engravings constitute the majority of Indus iconography, depicting bulls, buffalo, bison, tigers, elephants, rhinoceroses, and chimeras, often along with a stylized object that appears to be a manger or trough (Fig. 7). The majority of Indus seals are engraved with "unicorns," bulls in profile that were depicted with a single horn and wearing blankets and ornaments (Kenoyer 2013). Most also share a standardized shape - square faces with a height and width of $\sim 2.5 \mathrm{~cm}$. Despite this high degree of standardization, Indus seals were produced by many different groups of artisans (Franke-Vogt 1991, 1992; Jamison 2018; Kenoyer and Meadow 2010; Rissman 1989), indicating that production was divided among multiple communities of practice who relied on shared stylistic and technological conventions (Green 2010, 2016). Seal production was not even noticeably centralized, let alone under the control of a ruling class.

Nor, apparently was seal use. Seals have been found at nearly every structure at Mohenjo-daro (Franke-Vogt 1991; Parpola 1994). They are numerous in urban assemblages and abundant in many small settlements as well (e.g., Joshi and Parpola 1987; Shah and Parpola 1991). It is likely that seals and sealings were used in a variety of ways, including to make clay impressions over doors or the openings of containers, which allowed them to serve as an "administrative technology" analogous to the seals employed in southern Mesopotamia during the third millennium BC (e.g., Pittman 1994). One of the earliest sealings was used on a building at Harappa (Kenoyer and Meadow 2010), and a cache of 90 sealings was found at Lothal (Frenez and Tosi 2005). These sealings vary in shape, but most appear to have been used to close different kinds of lockers and containers, suggesting they were employed in a wide range of economic activities. Fairservis 


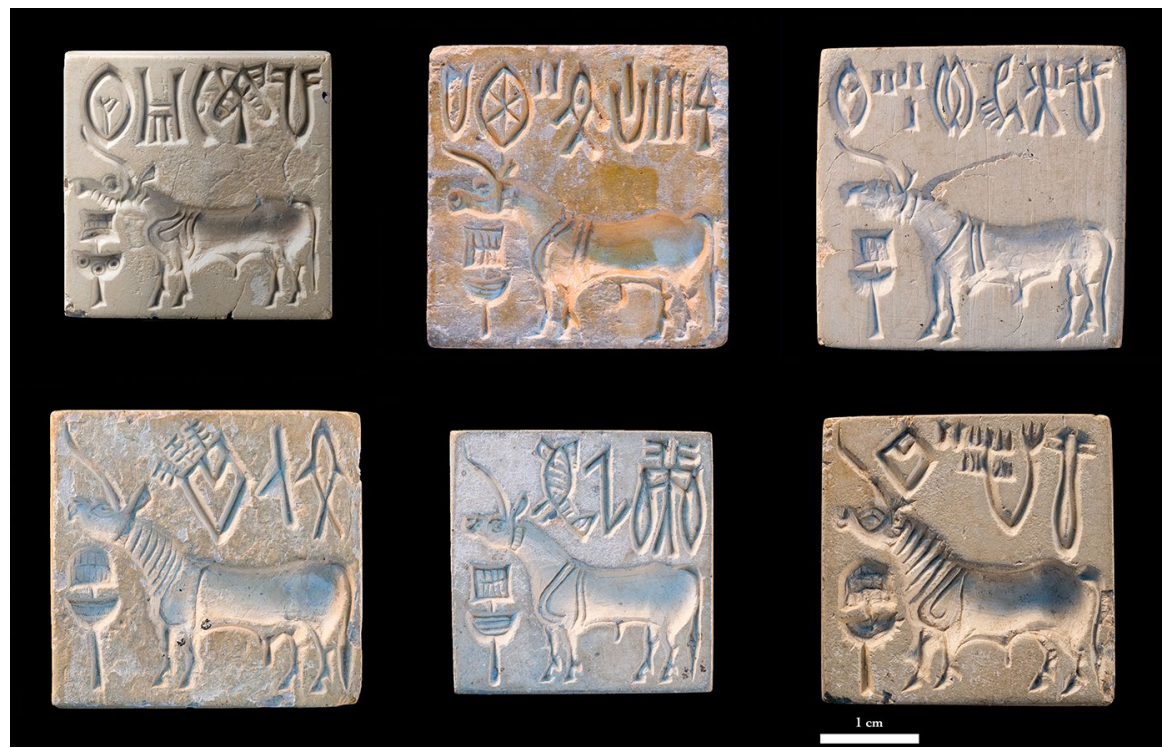

Fig. 7 A selection of unicorn stamp seals recovered from Mohenjo-daro. Like the majority of Indus seals, they are highly standardized, and all depict the same image. CISI Numbers|Archaeological Survey of India Accession Numbers: Top row (left to right): M-173|63.10/8, M-86|63.10/151, M-116|63.10/29: Bottom row (left to right): M-151|63.10/14, M-97|63.10/15, M-152|63.10/19. Photographs by the author

(1982) has argued that Indus seal motifs conveyed information about membership in different social groups. Some motifs were used by Indus corporate groups that interacted with settlements in Arabia and southern Mesopotamia (Vidale 2005), whereas others were confined to the large cities (Frenez and Vidale 2012). Based on the arrangement of seal motifs and their distribution at different sites, Indus seal motifs may represent the "public persona" of their users (Frenez 2018a). There are major differences in seal and sealing assemblages throughout the Indus civilization (Ameri 2013; Petrie et al. 2018). These differences indicate that there was not a single way in which seals, themselves highly standardized, were used (Petrie et al. 2018). The use of seals and the clay sealings may have played a role in balancing reciprocity among corporate groups in Indus cities and facilitating exchange across social boundaries, especially among urban strangers (Green 2020).

The complex technological processes that would have been necessary to support the political economy of the Indus civilization is one of the primary lines of evidence that proponents of the state-level paradigm have used to argue for the existence of stratified divisions among elites and commoners (Kenoyer 1992, 1997b, 2000). And yet, the locations of production and consumption appear to have been relatively spatially unconstrained. This wide distribution of craft activities has led many scholars to conclude that multiple groups of artisans retained control over the goods they produced. Technological styles tend to crosscut artisan groups, indicating a great deal of openness and knowledge sharing. The complexity of Indus crafts 
is a product of this openness and knowledge; it does not indicate that their production and distribution was under the control of a ruling class.

The only possible exception to this pattern of intermingled craft areas comes from a small number of specialized sites in Gujarat, where the mass production of some craft objects, such as shell bangles at Bagasara (Bhan et al. 2004), does, indeed, appear to be confined to small areas circumscribed by large stone walls. Such specialized sites contrast with large settlement centers where many crafts were produced, such as Dholavira, and may be associated with the interaction between Indus communities and local "Sorath Harappans," agro-pastoralists characterized by their own local material cultures (Possehl and Herman 1990). The degree to which interactions between Harappan and Sorath Harappan groups were extractive is subject to considerable debate (Chakraborty et al. 2018; Chase 2010, 2018; Chase et al. 2014a; Petrie 2013a, b; Wright 2010). While these well-protected production sites could certainly have restricted access to particular production stages, there is no evidence that the goods they produced were constrained to smaller group of consumers. After all, shell bangles are found throughout the entire Indus civilization.

\section{Evidence of Collective Action and Political Organization}

Large- and small-scale public buildings, settlement planning, and standardized craft goods-especially seals, weights and measures_are prime evidence of collective action in Indus cities, as they would have required the coordinated endeavor of people who belonged to different corporate groups. The Great Bath at Mohenjo-daro is a massive structure that contained a large paved bath assembled from tightly fitted baked bricks waterproofed with bitumen and supplied with pipes and drains that would have allowed control over the temperature and amount of water (Marshall 1931, p. 24). The Pillared Hall, near the Great Bath, is over $30 \mathrm{~m}$ on each side (Marshall 1931, p. 23). Harappa's Mound F also included large nonresidential structures, including an extensive foundation that Wheeler (1953) called a "Great Granary," despite a lack of evidence for grains or any real storage capacities (Fentress 1976; Wright 2010). At both Harappa and Mohenjo-daro, these large nonresidential structures were relatively accessible, prompting the dominant view that they were "public." The most elevated section of Dholavira lies behind a thick stone wall with a carefully constructed gateway, providing access to a series of deep reservoirs that were cut into the bedrock beneath the site (Bisht 2015). Each of these nonresidential structures required substantial labor, far more than would have been required to make even the most sophisticated craft ornament. At Mohenjo-daro, nonresidential structures were built atop brick platforms that were in and of themselves as substantial as the structures erected on top of them (Jansen 1994). Possehl supposes that just one of the "foundation" platforms at Mohenjo-daro would have required 4 million days of labor, or 10,000 builders working for more than a year (Possehl 2002, p. 103). Indus structures famously conform to streets and lanes, themselves aligned to astronomical phenomena (Wankze 1984), evidence of civic planning that crosscuts multiple neighborhoods. There is strong evidence that many of the hallmark technologies of Indus civilization, such as weights (Miller 2013) and seals (Franke-Vogt 
1991, 1993; Green 2015; Konasukawa and Koiso 2018), were highly standardized. Irrigation projects also constitute possible evidence of collective action. There is considerable debate regarding whether or not Indus agriculture involved substantial irrigation (Chakrabarti and Saini 2009; Miller 2006, 2015; Wright 2010; Wright et al. 2008). Given the diversity and dynamism of the Indus civilization's alluvial environments, it is possible that collective authorities were involved in the management of Indus agriculture (Miller 2015; Petrie et al. 2017).

Such evidence for collective action has led some scholars to argue that the Indus civilization had a powerful cadre of elusive rulers. Some agree with early arguments that the Indus was a stratified military state but argue that it was a powerful and class-stratified indigenous empire that could have sent invading forces outward from South Asia (Dhavalikar 1995; Lal 1993). Proponents of a more current imperial paradigm suggest that Indus collective action was coordinated by a powerful centralized state (Ratnagar 2016). Neither view adequately accounts for the inclusive and distributed nature of Indus wealth and power, both holding that collective action could only have been achieved by a powerful centralized state reinforced by political and economic inequality. Some have even argued that the lack of evidence of inequality is itself actually evidence for the strength of the civilization's faceless ruling class, who were able to suppress the visible materialization of these boundaries (e.g., Miller 1985). Of course, the center of all this supposed coercive imperial power has yet to be identified. Rather than arguing that evidence of their absence attests to the power of the Indus civilization's ruling class, it is far more reasonable to argue that evidence of their absence in fact indicates their absence.

It is conspicuous that the sites commonly identified as Indus cities are roughly equidistant from one another. This settlement pattern has been argued to reflect a civilization of discrete city-states that may have maintained control over their surrounding hinterlands, but not over one another (Chakrabarti 2000; 2009; Kenoyer 1997a; Possehl 2002; Shinde 2016; Sinopoli 2015; Wright 2010). However, evidence of coercive urban-rural dynamics has not been identified. Rural settlements instead appear to have benefited from their contact with the cities (Parikh and Petrie 2019; Wright et al. 2003, 2005), without incurring the vulnerabilities associated with living in a populous settlement (Petrie 2019). Moreover, the Indus civilization does not appear to have dominated its neighboring societies, such as the Ahar-Banas settlements on the west side of the Thar Desert (Raczek 2016), the Jodhpura cultural complex (Rizvi 2007, 2018), or the Kulli in Baluchistan (Possehl 1986; Wright 2016). The site of Gilund is particularly interesting; though it was not part of the Indus civilization, its occupants made prodigious use of seals and sealings (Ameri 2014).

There are no clear depictions of violence in Indus iconography, a striking fact given that warfare was the topic of much of the early art in the contemporary societies of Egypt and Mesopotamia (e.g., Aruz 2003). Indeed, it is widely held that the Indus civilization was relatively peaceful, both within its regions and in its interactions with its neighbors. Proponents of both the stateless and state-level paradigms argue that the Indus civilization lacked warfare (Kenoyer 1998; Possehl 2002), noting questions about the function of large fortification structures (Fentress 1976) and the flimsiness of copper blades for use as Indus weapons (Ratnagar 2004). This 
argument has been critiqued through comparative research that suggests that plenty of similarly non-mid-beamed weapons appear in bellicose Bronze Age societies and that, in absence of texts or graphic depictions, large-scale walls and platforms may in fact be defensive in nature (Cork 2005, 2011). Some scholars have cited this lack of violence to argue that trade and technology were the basis for the emergence of "merchant elites" (Kenoyer 1997b). Thus far, however, only relatively small numbers of Indus craft goods moved interculturally, and no clear evidence of Indus markets have been identified. It is thus unlikely that a distinct class of merchants-social groups that enriched themselves through exclusive control of the profit gained by moving goods to far-away locations-existed.

\section{Equal Distributions of Burial Wealth}

The lack of rich Indus tombs has long been conspicuous (Malik 1968; Sastri 1965), despite the fact that many burials have been excavated throughout the Indus civilization (Kenoyer and Meadow 2016; Robbins Schug n.d.; Robbins Schug and Walimbe 2016; Shinde 2016; Vats 1940; Wheeler 1947). Indus cemetery sites are, without exception, densely used, highly disturbed, and stratigraphically complex, comprising numerous overlapping graves and redeposited remains. There is strong patterning in the location of Indus cemeteries. At Farmana, Kalibangan, Dholavira, and Rakhigarhi, cemeteries are between 500 and $1000 \mathrm{~m}$ from the main settlement area, suggesting a preference for burial grounds a short walk from the main settlement (Shinde et al. 2011). The cemetery sites that surround Harappa-Area G, Cemetery H, and R-37_ are particularly so, with 547 potential burials (Kenoyer and Meadow 2016). Despite this substantial sample, it is regularly argued that Harappa's cemeteries were used by only a small proportion of the site's population (Cork 2011; Kenoyer and Meadow 2016; Robbins Schug et al. 2012), an argument that avoids addressing the relatively even distribution of wealth in Indus graves. A common assertion is that rich Indus graves are unavailable because the elite may have been deposited in rivers or cremated (Kenoyer and Meadow 2016). This latter suggestion is puzzling, as cremations are hardly archaeologically invisible (e.g., Williams 2015). If the reported graves indeed represent only a small segment of Harappa's population, their capacity to inform us about wealth distribution would be limited. However, their stratigraphic complexity and proximity to intense urban occupations may instead reflect the frequent reuse of cemetery land. In brief, there is no convincing evidence that there are socioeconomic strata that are not represented within Harappa's cemeteries. Indus cemeteries can thus offer some useful insights into distributions of burial wealth.

Indus burial goods typically include pots and personal ornaments. Rissman (1988) compiled data from a sample of graves from Harappa (Wheeler 1947, pp. 58-130), Lothal (Rao 1979, pp. 137-69), and Mohenjo-daro (Marshall 1931, p. 184). The items interred in burials were different from those stored beneath houses, which were more likely to contain raw craft materials such as metal and stone. The most variable attribute of the grave good assemblages was the number of ceramic vessels, which Rissman (1988, p. 214) states "range in number from 
zero to seventy-two," though in the table accompanying his article the highest number of vessels was 37. Most of the graves had been cut by later internments, and unsurprisingly those that contained the most goods were the least disturbed. The type and number of beads in burials varied, and the material chosen appears to have been regionally specific_-beads were more common at Mohenjo-daro and absent at Lothal, where goat horn cores were favored. Vessels were more common at Harappa.

Subsequent excavations have reinforced these patterns. Among 18 graves excavated at Kalibangan, 78 pots were interred in a rectangular grave without a skeleton (Sharma 1999, p. 88). The Farmana cemetery, about a kilometer from the settlement, included 57 burials, the "richest" of which contained 17 vessels; the poorest contained 2 (Shinde et al. 2011, p. 677). At Rakhigarhi, one grave, among the best preserved, had 37 vessels (Nath et al. 2015; Shinde et al. 2018b). Notable among the Rakhigarhi data are a number of multiple burials, a practice held over from the preurban contexts (Ajithprasad 2018), and also attested in Cemetery R-37 at Harappa. Multiple bodies were sometimes interred in a single grave, such as at Lothal (Pal 2014) and at Farmana, which excavators interpreted as a one-off interment of individuals who died around the same time (Shinde et al. 2018a). At Harappa, children and infants were not buried with pottery or ornaments (Robbins Schug n.d.). The number of pots interred with individuals increases with the age of the deceased at death.

Dholavira may again deviate from the broader pattern. Excavations at Dholavira have produced evidence of six burial structures in the site's cemetery (Bisht 2015). Given their location, these structures may be the sole examples of Indus tombs, but no human remains were recovered from the two that were excavated. A modest quantity of grave goods-beads and ceramic vessels-were recovered from the structures, but their stratigraphy was complex, and the excavators were not convinced that they had identified intact burial chambers (Bisht 2015). It is possible that like many Bronze Age tombs, the Dholavira tombs had been disturbed after they were used to inter human remains. However, it is also possible that they followed the broader pattern evident at other Indus cemeteries; these structures and the cemeteries surrounding them may have been reused, just as the burial land surrounding other Indus cities was frequently disturbed to accommodate the internment of more individuals.

While there are not considerable discrepancies in the wealth interred with different individuals, there are instances of interpersonal violence and a long-term trend of increases in the occurrence of particular kinds of pathologies (Kennedy 2002; Lee et al. 2019 Lovell 2016; Robbins Schug and Blevins 2016; Robbins Schug et al. 2012, 2013, n.d.). The documented violence during the Urban phase at Harappa comes exclusively from multiple burials (Robbins Schug n.d.). Immature skeletons were found to lack skeletal pathology (Robbins Schug and Blevins 2016; Robbins Schug et al. 2013). Leprosy and certain forms of maxillary infection are evident in the skeletal remains from the Urban phase at Harappa, though the individuals with evidence of these ailments were interred in the same cemeteries as otherwise healthy individuals (Robbins Schug et al. 2013). Robbins Schug et al. (2012) draw on this evidence to argue that the Indus civilization was less peaceful than proponents of 
both state-level and stateless paradigms have argued. Still, it is important to recognize that interpersonal violence does not equate to warfare.

\section{Trajectories of Deurbanization}

After 1900 BC, major changes impacted nearly every aspect of life in the Indus civilization. Still, many scholars have noted the continuation of many elements of Indus material culture in the wake deurbanization, suggesting that the process was a complex transformation (e.g., Petrie 2017). As landscape datasets have grown especially since 2000, it has become increasingly apparent that environmental changes played an important role in Indus deurbanization (Giosan et al. 2012; Madella and Fuller 2006; Petrie et al. 2017; Wright 2010). There is an apparent correlation between Indus deurbanization and a weakening of the Indian summer monsoon associated with the broader 4.2k event (Dixit et al. 2014a, b). There also are clear correlations between shifting settlement locations and deurbanization that resulted in an eastward shift in population (e.g., Green and Petrie 2018; Madella and Fuller 2006; Petrie et al. 2017; Teramura and Uno 2006; Wright 2010). Surveys have revealed many concentrations of sites in northwest India with Indus material (Chakrabarti and Saini 2009; Dangi 2018; Joshi et al. 1984; Kumar 2009; Parmar et al. 2013; Pawar 2012; Sharan et al. 2013; Singh et al. 2010, 2011, 2018, 2019). This was perhaps due to the fact that summer and winter rainfall systems overlapped in the region, which ensured that alternative sources of water were available (Petrie et al. 2017).

Aside from the excavation of ephemeral "Late Harappan" layers at Harappa and Dholavira, few clear excavation data are available from the post-Urban phase (c. 1900-1300 BC). Only two major post-Urban sites-Bhagwanpura (Joshi and Madhu 1993) and Hulas (Dikshit 1984) — have been extensively excavated, and neither produced the clear site plans or structure foundations analogous to those found in Indus cities. It would thus appear unlikely that there were palaces in the post-Urban phase. Post-Urban ceramic vessel forms are clearly related to early urban forms, but many signature elements of Urban phase material culture disappeared (Wright 2012). With deurbanization, writing, seals, weights, long-distance exchange, and large nonresidential architecture all disappeared (Petrie 2017, 2019). However, small settlements continued and even increased in many parts of northwest India, which may be evidence of rural resilience that carried through urbanization and deurbanization (Petrie 2019). There was a significant increase in the quantity of faience ornaments produced in northwest India (Shinde et al. 2008; Uesugi et al. 2013), which may reflect the application of specialized knowledge to the mass production of objects that do not require raw materials from long-distance exchange networks.

Visceral evidence of the social impact of deurbanization is apparent in skeletal material from Harappa's post-Urban cemeteries. With the loss of Indus cities there appear to have been deterioration in overall health and increases in physical violence that affected some portions of the Indus population more than others (Robbins Schug et al. 2013). The health of the post-Urban population at Harappa sharply declined, with pronounced increases in the frequency of diseases like tuberculosis and leprosy (Robbins Schug et al. 2013, p. 4). There may also have been a hardening of social 
boundaries. At Harappa, a distinction in burials appears in the differential treatment of sick and healthy individuals (Robbins Schug et al. 2013). Individuals with leprosy were confined to Area $\mathrm{G}$, outside of the city walls, suggesting that sufferers had perhaps been singled out and confined to particular cemeteries. Worse still, there is evidence of a considerable increase in interpersonal violence, especially toward biological females and immature individuals. Dental lesions and increased vascularization indicate that the post-Urban population of Harappa faced vitamin $\mathrm{C}$ deficiency, anemia, and metabolic disorders, a dramatic change from the Urban phase (Robbins Schug and Blevins 2016). These changes certainly raise questions about a larger process of deurbanization that may have ended Indus egalitarianism. Indus cities may have acted as a possible brake on inequality, which increased sharply in their wake. This hypothesis is worthy of further investigation.

\section{Discussion}

The relative egalitarianism of the Indus civilization has been evident since the earliest excavations at Mohenjo-daro, but there has since been remarkable reluctance to investigate it. This is true both of scholars who assumed the Indus civilization was led by priest-kings and by those who thought that the Indus lacked a state. The inability to account for Indus egalitarianism has resulted in the omission of Indus civilization from comparative discussions of social complexity, which now acknowledge a much broader range of nonhierarchical, noncoercive, and nonelite-centered social formations (e.g., Feinman and Carballo 2018). Indus archaeology has much to contribute to this area of study, and my aim in this article is to encourage a deeper exploration of the implication that complex societies can be egalitarian. However, to grow the critical role for Indus civilization in comparative archaeology, Indus archaeologists need to lose some bad habits.

Foremost among these is the tendency to lament the lack of data from the Indus civilization, or to argue that Indus datasets are unusable because they were collected so long ago. Sure, the Indus civilization could use more research, but the same could be said for most early complex societies. This kind of argument has promoted the view that we simply do not know enough about Indus civilization to explore the implications of what we do know. While there have probably been more surveys and excavations in Mesoamerica, Mesopotamia, and the Mediterranean, the last century of Indus archaeology in South Asia has been an enormously rich and successful endeavor. Building on the talents of the network of researchers cultivated in the Archaeological Survey of India, Marshall rediscovered one of the world's earliest Bronze Age societies (Lahiri 2005). Mackay's (1938, p. xvi) excavations at Mohenjo-daro, which incorporated a subdatum in an effort to meticulously track changes in material culture through time, were far more methodologically advanced than many contemporary excavations in Mesopotamia. Subsequent generations of South Asian archaeologists redrew the map of the ancient world. Excavations at numerous Indus settlements, such as Lothal (Rao 1979), Dholavira (Bisht 2015), Kalibangan (Lal 2003; Lal et al. 2015), and Kot Diji (Khan 1965), have greatly enhanced our understanding of the Indus civilization. A strong tradition 
of survey has revealed hundreds of small settlements and produced distribution data that rival many contemporary archaeological datasets (Chakrabarti and Saini 2009; Green et al. 2019; Green and Petrie 2018; Joshi et al. 1984; Kumar 2009; Mughal 1997; Mughal et al. 1996; Parmar 2012; Pawar 2012; Possehl 1999; Rajesh 2011; Shaffer 1987; Sharan 2018; Singh et al. 2010, 2011, 2018, 2019; Suraj Bhan 1969, 1975; Wright et al. 2003, 2005). Like all archaeological evidence, Indus datasets have their limitations, but it is evident that palaces, elaborate tombs, and individualaggrandizing monuments are not present at Indus sites. This lack of stratification does not diminish the role of Indus civilization in the study of social complexity; in fact, it does the opposite. Rather than following the general rules proposed for other complex societies, the Indus civilization challenges us to rethink the fundamental connections between collective action and inequality. Sometimes an absence of evidence is indeed evidence of absence, especially when you have spent a century looking for it.

Collective action can increase without the guidance of a managerial ruling class. Indus communities devised ways of building a neighborhood platform or wall, incorporating labor from multiple corporate groups, with minimal coercion or exclusionary politics. They maintained a standardized system of weights and measures across the broad extent of the Indus civilization over centuries, which likely entailed the consent of generations of corporate groups. However, none of these corporate groups appear to have used these standardized systems to establish permanent dominance over the others. Indus communities were likely home to people with a wide range of identities (e.g., Clark 2003; Kenoyer 1998; Rizvi 2011). Thus, the emergent nature of Indus collective action may explain the materialization of identities that crosscut local social groups, be they in the cities (e.g., Davis 2018) or in rural Gujarat (e.g., Chase et al. 2014a). These corporate groups drove the urbanization process, which required the production of many generalized "public goods"-streets and drainage systems, large and small buildings with public access, and informational and regulatory technologies like weights and seals that would have facilitated exchange among different corporate groups (e.g., Green 2020).

The absence of a ruling class and relative egalitarianism does not necessarily indicate that there were no other forms of inequality in Indus society. Indeed, differences in the treatment of young and old (Robbins Schug n.d.), the noted heterogeneity in Indus material culture (Petrie et al. 2018), along with the likely presence of at least three genders (Clark 2003, 2016) and differences in the mortuary treatment of people belonging to different biological sexes (Robbins Schug et al. 2012), and possible social hierarchies based on potential differences in urban infrastructures (Rizvi 2011; Wright 2010; Wright and Garret 2018) all suggest that there were a range potential cleavage planes in Indus society. While many differences became more pronounced with deurbanization (Robbins Schug et al. 2013), relative equality may have prevailed across a wide range of identities when Indus cities were at their height. These other potential loci of inequality deserve further research; however, none provide evidence of a ruling class.

If a ruling class is not a prerequisite for collective action, then collective action must have been an emergent outcome of interactions among heterarchical corporate groups. Comparative archaeology reveals that cooperation, as opposed to coercion, 
is a key mechanism for generating collective action (Carballo 2013; DeMarrais 2016). It is reasonable to theorize that Indus corporate groups devised means of governing collective action without permanently elevating one over the others, such as agreeing to standardized protocols for craft production. One way may have been through the creation of specialized spaces for exchange, negotiation, and interaction at the spatial interstices between corporate groups, such as between neighborhoods or along important streets and roads. I have argued that such "small public structures" are evident at Mohenjo-daro, where urbanization appears to have resulted from the initial aggregation of larger corporate entities, represented in the large structures constructed in Block 1 and 11 of Mohenjo-daro's DK-G area (Green 2018). These initial large corporate compounds were replaced over time by houses organized along the streets' grid at a time when economic specialization was increasing and "small public structures" appeared between neighborhoods. Corporate groups that began the Urban phase as generalists who, over time, divided into smaller more specialized corporate entities, nonetheless maintained a high degree of consensus. The construction of specialized spaces may even have ensured that none of Mohenjo-daro's increasingly specialized corporate groups was able to accumulate wealth at the expense of others (Green 2018).

Egalitarianism thus appears to have been a boon to collective action in the Indus civilization. Corporate groups may simply be more willing to invest in collective endeavors if benefits are not constrained to a restricted subset of elites. At the same time, the efforts of a subset of elites to exact labor from everyone else may restrict collective action by placing boundaries between the corporate groups that make decisions and those whose labor materializes those decisions. A positive relationship between egalitarianism and collective action can also explain certain heterarchical dynamics. In societies with a ruling class, heterarchy among ruling groups may restrict the overall scope for collective action by dividing efforts to exact labor from the same pool of commoners. However, when heterarchy expands the number of unstratified corporate groups in an egalitarian society, it theoretically increases the potential for emergent, consensual, and cooperative collective action. Heterarchy, then, may potentially act as a brake on coercive power among social groups, and societies with a larger number of heterarchical social groups may inculcate more such brakes, restricting coercive authority among different groups on the whole. Rather than arguing that the Indus civilization was heterarchical, we should ask whether heterarchical corporate groups were more numerous in the Indus civilization than in early societies with exclusionary elites, and if so, why? Exploring these questions may reveal how the same social processes, like urbanization and economic growth, can result in different social outcomes.

The increase in economic activity that accompanied Indus urbanization supports the idea that concentrating human activities and fostering specialization drives economic growth. A major indicator of this growth is craft specialization, but it has long been clear that there was not a simplistic relationship between specialization, exchange, urbanism, states, or other traditional harbingers of social complexity (Costin 1991; Inomata 2008; Schortman and Urban 2004; Sinopoli 2011). The lack of a ruling class in Indus cities supports the argument that early cities were not invariably seats of elite power (e.g., Jennings and Earle 2016). It 
would be worthwhile to explore the connection between specialization and egalitarian growth in the Indus, which may reveal different forms of economic attachment. Certain crafts are associated with one another at Indus sites, and production facilities are occasionally found in association with large structures (e.g., Green 2018; Sher and Vidale 1985), a form of attachment that is curious given the lack of a ruling class. Though the notion of attached specialization has been repeatedly critiqued (e.g., Costin 1991), it remains a common assertion that the control of attached specialists is a key indicator of social complexity (e.g., Nash 2019). By definition, such attachments can exist only in a society divided into ruling and specialist classes. Indus artisans may have instead formed attachments to many different kinds of corporate groups. The nature of these attachments between different kinds of heterarchical corporate groups remains an important topic for future research.

Research on Indus wealth and value suggests that people in the Indus valued distinct kinds of things differently (Kenoyer 1992, 2000; Miller 2008a; Rissman 1988). However, the same can probably be said for all societies. Ethnographic research on many societies that lack a ruling class rely on different forms of value in different situations. Some devised entire currencies to "... arrange marriages, establish the paternity of children, head off feuds, console mourners and funerals, seek forgiveness in the case of crimes, negotiate treaties, [and] acquire followers" (Graeber 2011, p. 130). Though certain categories of objects are rare in the Indus, their distribution does not appear to be particularly restricted, at least within the cities, strongly suggesting that little fell within the exclusive control of a particular ruling class. While some Indus graves contained more ceramic vessels than others, no Indus graves featured retainer sacrifice or monumental aggrandizements of a single ruler or family, such as Pepy's pyramid in ancient Egypt (Wenke 2009, p. 2) or the Shang China tombs (Campbell 2014, p. 99). The absolute range of wealth distributions in the Indus civilization has not been directly compared to other early complex societies, without which it is difficult to ascertain whether wealth differentials in the Indus were commensurate.

One of the most positive developments in Indus archaeology has been the dramatic increase in data and interest in the small settlements of the Indus civilization. In southern Mesopotamia, settlements of different sizes exhibited qualitative differences; towns, cities, and villages all performed different roles in the broader landscape (e.g., Adams 1966). In the Indus, it is unclear the degree to which small settlements were distinct from the cities. Wright et al. (2003, 2005) have argued that the small settlements in the Upper Indus Basin were "satellites" of urban communities and as such exhibited the same degree of complexity as the cities. On the other hand, Parikh and Petrie (2019) have argued that the small settlements of northwest India were "rural" in character, and although their communities appear to have had access to exotic goods, it has not been established that they hosted a population of craft specialists. It remains an open question whether small settlements were qualitatively different from one another or from the cities; until this question is resolved, it will be difficult to ascertain if Indus egalitarianism extended across its broader landscapes. 


\section{Conclusion}

The Indus civilization lacks evidence of palaces, elaborate tombs, aggrandizing monuments, and significant discrepancies in grave goods. At the same time, Indus cities boast considerable evidence of sophisticated technologies, commodious houses, large-scale nonresidential architecture, and long-distance interaction. The Indus civilization was perhaps the world's most egalitarian early complex society, defying long-held presumptions about the relationships between urbanization and inequality in the past. Residents of Indus cities enjoyed a relatively high standard of Bronze Age living. Unfortunately, generations of archaeologists have largely overlooked this phenomenon, focusing instead on contextualizing the Indus within a rigid trait-driven set of evolutionary categories. Some have argued that the Indus was an empire, some that it was stateless, and others that it was a state-level society led by competitive merchant elites. None of these arguments satisfactorily addresses the extent, diversity, and variability of the Indus civilization as a whole. Archaeological data from South Asia have greatly improved since the Indus state debate that culminated in the 1990s (e.g., Petrie 2019; Ratnagar 2016; Shinde 2016; Wright 2018); numerous Indus sites are now known to archaeologists, and the environmental contexts in which South Asia's first urbanization and deurbanization occurred are now much clearer. To identify inequality, and class in particular, archaeologists have honed a strong set of arguments about mortuary data, palace assemblages, aggrandizing monuments, and written records (Feinman 1995), and efforts are underway to develop similar indices for household data as well (Kohler and Smith 2018). In a century of research on the Indus civilization, archaeologists have not found evidence for a ruling class that is comparable to that recovered in many other early complex societies. It is therefore time to address the egalitarianism of Indus civilization. Urbanization, collective action, and technological innovation are not driven by the agendas of an exclusionary ruling class and can occur in their total absence. The priest-king is dead. The Indus civilization was egalitarian, but this is not because it lacked complexity; rather, it is because a ruling class is not a prerequisite for social complexity.

Acknowledgments I would like to thank Gary Feinman for the invitation to write this article and encouraging me to pursue my argument that Indus civilization's egalitarianism has critical comparative implications, highlighting that inequality is a critical topic for future research on South Asia's earliest cities. I am grateful to the Archaeological Survey of India for supporting my work and to Vasant Shinde and Ravindra Nath Singh for ongoing collaborations in the field. Darryl Wilkinson and Cameron Petrie provided invaluable comments on an early draft of the manuscript, and Toby Wilkinson and Thomas Leppard gave insightful feedback as the manuscript developed. Aftab Alam, Nancy Highcock, Emma Lightfoot, and Andreas Angourakis were an endless source of useful and fascinating discussions about comparative approaches to complex societies. This paper was shaped by long-running discussions I have had with Rita Wright and Sneh Patel, and the topic of inequality in the Indus has been on my mind ever since I completed my undergraduate honors thesis with John Kantner. I would like to thank Oliver Dunn and Chloe Ashley for inviting my family to join them for a week on the Isle of Raasay, which provided a unique and inspiring environment for writing the first draft of this article. I would also like to thank the seven anonymous peer reviewers who provided invaluable responses, and Linda Nicholas, whose suggestions were essential. I completed this work while working on the European Research Council-funded TwoRains project (Horizon 2020 grant no. 648609) and the Global Challenges Research Fund's TIGR ${ }^{2}$ ESS Project (Biotechnology Sciences Research Council grant number BB/P027970/1). These projects gave me 
the vital opportunity to collaborate with Jennifer Bates, Alessandro Ceccarelli, Francesc Conesa, Arnau Garcia-Molsosa, Hector Orengo, Danika Parikh, Akshyeta Suryanarayan, Meltem Cemre Üstünkaya, Joanna Walker, and Nathan Wright. Most importantly, I would like to dedicate this article to Lillian, Henry, and Isaac Green. Any and all faults in the text or the ideas presented therein are entirely my own.

Open Access This article is licensed under a Creative Commons Attribution 4.0 International License, which permits use, sharing, adaptation, distribution and reproduction in any medium or format, as long as you give appropriate credit to the original author(s) and the source, provide a link to the Creative Commons licence, and indicate if changes were made. The images or other third party material in this article are included in the article's Creative Commons licence, unless indicated otherwise in a credit line to the material. If material is not included in the article's Creative Commons licence and your intended use is not permitted by statutory regulation or exceeds the permitted use, you will need to obtain permission directly from the copyright holder. To view a copy of this licence, visit http://creativecommons.org/licen ses/by/4.0/.

\section{References Cited}

Adams, R. M. (1966). The Evolution of Urban Society: Early Mesopotamia and Prehispanic Mexico, Aldine, Chicago.

Agrawal, D. P. (2007). The Indus Civilization: An Interdisciplinary Perspective, Aryan Books International, New Delhi.

Ajithprasad, P. (2002). The pre-Harappan cultures of Gujarat. In Settar, S., and Korisettar, R. (eds.), Indian Archaeology in Retrospect Volume II Protohistory: Archaeology of the Harappan Civilization, ICHR Manohar, Delhi, pp. 129-158.

Ajithprasad, P. (2018). Early Harappan burials and Kachchh. History Today 15: 21-33.

Ajithprasad, P., and Sonawane, V. H. (2011). The Harappa culture of north Gujurat: A regional paradigm. In Osada, T., and Uesugi, A. (eds.), Linguistics, Archaeology, and the Human Past, Occasional Paper 12, Research Institute for Humanity and Nature, Kyoto, pp. 223-269.

Algaze, G. (2008). Ancient Mesopotamia at the Dawn of Civilization: The Evolution of an Urban Landscape, University of Chicago Press, Chicago.

Ameri, M. (2013). Regional diversity in the Harappan world: The evidence of the seals. In Abraham, S. A., Gullapalli, P., Raczek, T. P., and Rizvi, U. Z. (eds.), Connections and Complexity: New Approaches to the Archaeology of South Asia, Left Coast Press, Walnut Creek, CA, pp. 355-374.

Ameri, M. (2014). Report on the seal impressions and related small finds. In Shinde, V., Raczek, T. P., and Possehl, G. (eds.), Excavations at Gilund: The Artifacts and Other Studies, Museum of Archaeology and Anthropology, University of Pennsylvania, Philadelphia, pp. 159-209.

Aruz, J. (2003). Art of the first cities: The third millennium BC from the Mediterranean to the Indus. In Aruz, J., and Wallenfels, R. (eds.), Art of the First Cities: The Third Millennium BC from the Mediterranean to the Indus, Metropolitan Museum of Art, New York, and Yale University Press, New Haven, pp. 3-10.

Baadsgaard, A., Monge, J., Cox, S., and Zettler, R. L. (2011). Human sacrifice and intentional corpse preservation in the Royal Cemetery of Ur. Antiquity 85: 27-42.

Bates, J. (2019a). Oilseeds, spices, fruits and flavour in the Indus civilisation. Journal of Archaeological Science: Reports 24: 879-887.

Bates, J. (2019b). The published archaeobotanical data from the Indus civilisation, South Asia, c. 32001500 BC. Journal of Open Archaeology Data 7: 5.

Belcher, W. (2003). Fish exploitation of the Indus Valley tradition. In Weber, S., Belcher, W., and Miller, L. (eds.), Indus Ethnobiology: New Perspectives from the Field, Lexington Books, Lanham, MD, pp. $95-176$.

Bhan, K., and Ajithprasad, P. (2012). Excavations at Shikarpur 2007-2008: A coastal port and craft production center of the Indus civilization in Kutch, India. Report submitted to harappa.com.

Bhan, K., Sonawane, V. H., Ajithprasad, P., and Pratapchandran, S. (2004). Excavations of an important Harappan trading and craft production center at Gola Dhoro (Bagasra), on the Gulf of Kutch, Gujarat, India. Journal of Interdisciplinary Studies in History and Archaeology 1: 153-158. 
Biagi, P., Starnini, E., and Michniak, R. (2018). Chert mines and chert miners: The material culture and social organization of the Indus chipped stone workers, artisans and traders in the Indus Valley (Sindh Pakistan). In Kenoyer, J., Frenez, D., Jamison, G., Law, R., Vidale, M., and Meadow R. (eds.), Walking with the Unicorn: Social Organization and Material Culture in Ancient South Asia: Jonathan Mark Kenoyer, Felicitation Volume, Archaeopress Archaeology, Summertown, Oxford, pp. $68-89$.

Bisht, R. S. (1987). Further excavations at Banawali: 1983-1984. In Pande, B., Chattopadhyaya, B., and Ghosh, A. (eds.), Archaeology and History: Essays in Memory of Shri A. Ghosh, Agam Kala Prakashan, Delhi, pp. 135-156.

Bisht, R. S. (2015). Excavations at Dholavira, Archaeological Survey of India, Delhi.

Blanton, R. E. (1994). Houses and Households: A Comparative Study, Plenum Press, New York.

Blanton, R. E. (1998). Beyond centralization: Steps toward a theory of egalitarian behavior in archaic states. In Feinman, G., and Marcus, J. (eds.), Archaic States, School of American Research Press, Santa Fe, NM, pp. 135-172.

Blanton, R. E., and Fargher, L. F. (2008). Collective Action in the Formation of Pre-Modern States, Springer, New York.

Blanton, R. E., and Fargher, L. F. (2016). How Humans Cooperate: Confronting the Challenges of Collective Action, University Press of Colorado, Boulder.

Blanton, R. E., Feinman, G. M., Kowalewski, S. A., and Peregrine, P. N. (1996). A dual-processual theory for the evolution of Mesoamerican civilization. Current Anthropology 37: 1-14.

Bogaard, A., Fochesato, M., and Bowles, S. (2019). The farming-inequality nexus: New insights from ancient western Eurasia. Antiquity 93: 1129-1143.

Bogaard, A., Styring, A., Whitlam, J., Fochesato, M., and Bowles, S. (2018). Farming, inequality, and urbanization: A comparative analysis of late prehistoric northern Mesopotamia and southwestern Germany. In Kohler, T., and Smith, M. (eds.), Ten Thousand Years of Inequality, University of Arizona Press, Tucson, pp. 201-229.

Broodbank, C. (2013). The Making of the Middle Sea, Thames and Hudson, London.

Brumfiel, E. M. (1995). Heterarchy and the analysis of complex societies: Comments. In Ehrenreich, R., Crumley, C., Levy J., and Fitzhugh, W. (eds.), Heterarchy and the Analysis of Complex Societies: Comments, American Anthropological Association, Arlington, VA, pp. 125-131.

Brumfiel, E. M., and Earle, T. (1989). Specialization, Exchange and Complex Societies, Cambridge University Press, Cambridge.

Campbell, R. B. (2014). Transformations of violence: On humanity and inhumanity in ancient China. In Campbell R. B., (ed.), Violence and Civilization: Studies of Social Violence in History and Prehistory, Oxbow Books, Oxford, pp. 94-118.

Carballo, D. (2013). Cooperation and Collective Action, University Press of Colorado, Boulder.

Chakrabarti, D. K. (2000). Mahajanapada states of early historic India. In Hansen, M. H. (ed.), A Comparative Study of Thirty City-State Cultures, Royal Danish Academy of Sciences and Letters, Copenhagen, pp. 375-392.

Chakrabarti, D. K. (2009). India: An Archaeological History: Palaeolithic Beginnings to Early Historic Foundations, 2nd ed., Oxford University Press, New Delhi.

Chakrabarti, D. K. (2014). Distribution and features of the Harappan settlements. In Chakrabarti, D. K., and Lal, M. (eds.), History of India: Protohistoric Foundation, Vivekanand International Foundation, New Delhi, pp. 98-143.

Chakrabarti, D. K., and Saini, S. (2009). The Problem of the Sarasvati River and Notes on the Archaeological Geography of Haryana and Indian Panjab, Aryan Books International, New Delhi.

Chakraborty, K. S., Chakraborty, S., Le Roux, P., Miller, H. M.-L., Shirvalkar, P., and Rawat, Y. (2018). Enamel isotopic data from the domesticated animals at Kotada Bhadli, Gujarat, reveals specialized animal husbandry during the Indus civilization. Journal of Archaeological Science: Reports 21: 183-199.

Channarayapatna, S. (2018). A Study of Animal Utilization Strategies from Early to Late Harappan Periods in Haryana, Research Group for South Asian Archaeology, Archaeological Research Institute, Kansai University, Osaka.

Chase, B. (2010). Social change at the Harappan settlement of Gola Dhoro: A reading from animal bones. Antiquity 84: 528-543.

Chase, B. (2018). Family matters in Harappan Gujarat. In Frenez, D., Jamison, G. M., Law, R., Vidale, M., and Meadow, R. (eds.), Walking with the Unicorn: Social Organization and Material Culture in Ancient South Asia, Archaeopress, Oxford, pp. 99-114. 
Chase, B., Ajithprasad, P., Rajesh, S. V., Patel, A., and Sharma, B. (2014a). Materializing Harappan identities: Unity and diversity in the borderlands of the Indus civilization. Journal of Anthropological Archaeology 35: 63-78.

Chase, B., Meiggs, D., Ajithprasad, P., and Slater, P. A. (2014b). Pastoral land-use of the Indus civilization in Gujarat: Faunal analyses and biogenic isotopes at Bagasra. Journal of Archaeological Science 50: 1-15.

Chase, B., Meiggs, D., Ajithprasad, P., and Slater, P. A. (2018). What is left behind: Advancing interpretation of pastoral land-use in Harappan Gujarat using herbivore dung to examine biosphere strontium isotope (87 Sr/ $86 \mathrm{Sr}$ ) variation. Journal of Archaeological Science 92: 1-12.

Childe, V. G. (1929). The Most Ancient East, Alfred A. Knopf, New York.

Childe, V. G. (1950). The urban revolution. Town Planning Review 21: 3-17.

Chirikure, S. (2020). New perspectives on the political economy of Great Zimbabwe. Journal of Archaeological Research 28: 139-186.

Clark, J. (1990). Craft specialization and cultural complexity. Research in Economic Anthropology 12: 289-346.

Clark, S. R. (2003). Representing the Indus body: Sex, gender, sexuality, and the anthropomorphic terracotta figurines from Harappa. Asian Perspectives 42: 304-328.

Clark, S. R. (2016). The Social Lives of Figurines: Recontextualizing the Third-Millennium-BC Terracotta Figurines from Harappa (Pakistan), Peabody Museum of Archaeology and Ethnology and American School of Prehistoric Research, Harvard University, Cambridge, MA.

Cork, E. (2005). Peaceful Harappans? Reviewing the evidence for the absence of warfare in the Indus civilisation of north-west India and Pakistan (c. 2500-1900 BC). Antiquity 79: 411-423.

Cork, E. (2011). Rethinking the Indus: A Comparative Re-evaluation of the Indus Civilisation as an Alternative Paradigm in the Organisation and Structure of Early Complex Societies, Archaeopress, Oxford.

Costin, C. L. (1991). Craft specialization: Issues in defining, documenting, and explaining the organization of production. Archaeological Method and Theory 3: 1-56.

Costin, C. L., and Wright, R. P. (eds.) (1998). Craft and Social Identity, Archeological Papers No. 8, American Anthropological Association, Arlington, VA.

Cowgill, G. L. (2004). Origins and development of urbanism: Archaeological perspectives. Annual Review of Anthropology 33: 525-549.

Cowgill, G. L. (2015). Ancient Teotihuacan: Early Urbanism in Central Mexico, Cambridge University Press, Cambridge.

Crone, P. (1989). Pre-Industrial Societies: New Perspectives on the Past, Blackwell, Oxford.

Crumley, C. L. (1995). Heterarchy and the analysis of complex societies. In Ehrenreich, R., Crumley, C. L., and Levy, J. E. (eds.), Heterarchy in the Analysis of Complex Societies, Archeological Papers No. 6, American Anthropological Association, Arlington, VA, pp. 1-5.

Dales, G. F., and Kenoyer, J. M. (1977). Shell working at ancient Balakot, Pakistan. Expedition: 19(2): 13-19.

Dales, G. F., Kenoyer, J. M., and Alcock, L. (1986). Excavations at Mohenjo Daro, Pakistan: The Pottery, University Museum, University of Pennsylvania, Philadelphia.

Dangi, V. (2018). Indus (Harappan) civilization in the Ghaggar Basin. In Uesugi, A. (ed.), Current Research on Indus Archaeology, Research Group for South Asian Archaeology, Archaeological Research Institute, Kansai University, pp. 56-168.

Davis, M. A. (2018). The Harappan 'veneer' and the forging of urban identity. In Frenez, D., Jamison, G. M., Law, R., Vidale, M., and Meadow, R. (eds.), Walking with the Unicorn: Social Organization and Material Culture in Ancient South Asia, Archaeopress, Oxford, pp. 145-160.

Delougaz, P. (1940). The Temple Oval at Khafajah, University of Chicago Press, Chicago.

DeMarrais, E. (2013). Understanding heterarchy: Crafting and social projects in pre-Hispanic northwest Argentina. Cambridge Archaeological Journal 23: 345-362.

DeMarrais, E. (2016). Making pacts and cooperative acts: The archaeology of coalition and consensus. World Archaeology 48: 1-13.

DeMarrais, E., and Earle, T. (2017). Collective action theory and the dynamics of complex societies. Annual Review of Anthropology 46: 183-201.

Dhavalikar, M. K. (1995). Cultural Imperialism: Indus Civilization in Western India, Books and Books, New Delhi. 
Dietrich, O., Heun, M., Notroff, J., Schmidt, K., and Zarnkow, M. (2012). The role of cult and feasting in the emergence of Neolithic communities: New evidence from Göbekli Tepe, south-eastern Turkey. Antiquity 86: 674-695.

Dikshit, K. N. (1984). Late Harappa in northern India. In Lal, B. B., and Gupta, S. P. (eds.), Frontiers of the Indus Civilization, Books and Books, Delhi, pp. 253-270.

Dixit, Y., Hodell, D. A., Sinha, R., and Petrie, C. A. (2014a). Abrupt weakening of the Indian summer monsoon at 8.2 kyr BP. Earth and Planetary Science Letters 391: 16-23.

Dixit, Y., Hodell, D. A., Sinha, R., and Petrie, C. A. (2014b). Oxygen isotope analysis of multiple, single ostracod valves as a proxy for combined variability in seasonal temperature and lake water oxygen isotopes. Journal of Paleolimnology 53: 35-45.

Durrani, F. A., Ali, I., and Erdosy, G. (1991). Further excavations at Rehman Dheri. Ancient Pakistan 1: 61-151.

Eerkens, J., and Bettinger, R. L. (2001). Techniques for assessing standardization in artifact assemblages: Can we scale material variability? American Antiquity 66: 493-504.

Fairservis, W. A. (1961). The Harappan civilization: New evidence and more theory. American Museum Novitates 2055: 1-35.

Fairservis, W. A. (1967). The origin, character, and decline of an early civilization. American Museum Novitates 2302: 1-48.

Fairservis, W. A. (1982). Allahdino: An excavation of a small Harappan site. In Possehl, G. L. (ed.), Harappan Civilization: A Contemporary Perspective, Aris and Phillips, Warminster, pp. 107-112.

Fairservis, W. A. (1989). An epigenetic view of the Harappan culture. In Lamberg-Karlovsky, C. C. (ed.), Archaeological Thought in America, Cambridge University Press, Cambridge, pp. 205-217.

Fargher, L. F., Blanton, R. E., Espinoza, V. Y. H., Millhauser, J., Xiuhtecutli, N., and Overholtzer, L. (2011). Tlaxcallan: The archaeology of an ancient republic in the New World. Antiquity 85: $172-186$.

Feinman, G. M. (1995). The emergence of inequality. In Price, T. D., and Feinman, G. M. (eds.), Foundations of Social Inequality, Plenum, New York, pp. 255-279.

Feinman, G. M. (2011). Size, complexity, and organizational variation: A comparative approach. CrossCultural Research 45: 37-58.

Feinman, G. M. (2013). The emergence of social complexity. In Carballo, D. M. (ed.), Cooperation and Collective Action, University Press of Colorado, Boulder, pp. 35-56.

Feinman, G. M. (2018). The governance and leadership of prehispanic Mesoamerican polities: New perspectives and comparative implications. Cliodynamics 9: 40.

Feinman, G. M., and Carballo, D. M. (2018). Collaborative and competitive strategies in the variability and resiliency of large-scale societies in Mesoamerica. Economic Anthropology 5: 7-19.

Feinman, G. M., and Marcus, J. (eds.) (1998). Archaic states, School of American Research Press, Santa Fe, NM.

Fentress, M. A. (1976). Resource Access, Exchange Systems and Regional Interaction in the Indus Valley, Ph.D. dissertation, Department of Anthropology, University of Pennsylvania, Philadelphia.

Fernández-Götz, M., and Krausse, D. (2017). Eurasia at the Dawn of History: Urbanization and Social Change, Cambridge University Press, Cambridge.

Flad, R. K., and Hruby, Z. (2008). "Specialized" production in archaeological contexts: Rethinking specialization, the social value of products, and the practice of production. In Hruby, Z., Flad, R. K., and Bennet, G. (eds.), Rethinking Craft Specialization in Complex Societies: Archaeological Analyses of the Social Meaning of Production. Archeological Papers No. 17, American Anthropological Association, Arlington, VA, pp. 1-19.

Flannery, K. V. (1972). The cultural evolution of civilizations. Annual Review of Ecology and Systematics 3: $399-426$.

Fochesato, M., Bogaard, A., and Bowles, S. (2019). Comparing ancient inequalities: The challenges of comparability, bias and precision. Antiquity 93: 853-869.

Franke-Vogt, U. (1991). Die Glyptik aus Mohenjo-Daro, von Zabern, Mainz am Rhein.

Franke-Vogt, U. (1992). Inscribed objects from Mohenjodaro: Some remarks on stylistic variability and distribution patterns. In Jarrige, C., Gerry, J., and Meadow, R. (eds), South Asian Archaeology 1989; Papers from the Tenth International Conference of South Asian Archaeologists in Western Europe, Prehistory Press, Madison, WI, pp. 103-112.

Franke-Vogt, U. (1993). Stratigraphy and cultural process at Mohenjo-daro. In Gail, A. J., and Mevissen G. J. R. (eds.), South Asian Archaeology 1991: Proceedings of the Eleventh International 
Conference of the Association of South Asian Archaeologists in Western Europe, Franz Steiner, Stuttgart, pp. 87-100.

Frenez, D. (2018a). Private person or public persona? Use and significance of standard Indus seals as markers of formal socio-economic identities. In Frenez, D., Jamison, G. M., Law, R., Vidale, M., and Meadow, R. (eds.), Walking with the Unicorn: Social Organization and Material Culture in Ancient South Asia, Archaeopress, Oxford, pp. 161-188.

Frenez, D. (2018b). The Indus civilization trade with the Oman Peninsula. In Cleuziou, S., and Tosi, M. (eds.), In the Shadow of the Ancestors: The Prehistoric Foundations of the Early Arabian Civilization in Oman - Second Expanded Edition, Ministry of Heritage and Culture, Oman, pp. 385-396

Frenez, D., and Tosi, M. (2005). The Lothal sealings: Records from an Indus civilization town at the eastern end of the maritime trade circuits across the Arabian Sea. In Perna, M., (ed.), Studi in onore Di Enrica Fiandra: Contributi di archaeologia egea e vicinorientale, De Boccard, Paris, pp. 65-103.

Frenez, D., and Vidale, M. (2012). Harappan chimaeras as 'symbolic hypertexts:' Some thoughts on Plato, chimaera and the Indus civilization. South Asian Studies 28: 107-130.

Fuller, D. Q. (2006). Agricultural origins and frontiers in South Asia: A working synthesis. Journal of World Prehistory 20: $1-86$.

García-Granero, J. J., Lancelotti, C., Madella, M., and Ajithprasad, P. (2016). Millets and herders: The origins of plant cultivation in semiarid North Gujarat (India). Current Anthropology 57: 149-173.

Giosan, L., Clift, P. D., Macklin, M. G., Fuller, D. Q., Constantinescu, S., Durcan, J. A., et al. (2012). Fluvial landscapes of the Harappan civilization. Proceedings of the National Academy of Sciences 109: E1688-E1694.

Good, I. L., Kenoyer, J. M., and Meadow, R. H. (2009). New evidence for early silk in the Indus civilization*. Archaeometry 51: 457-466.

Goodenough, W. H. (1978). Property, Kin, and Community on Truk, Archon Books, Hamden.

Graeber, D. (2011). Debt: The first 5,000 years, Melville, New York.

Green, A. S. (2010). Reconstructing operational sequences: A new methodology for the study of seal carving in the Indus civilization. Man and Environment 35: 15-34.

Green, A. S. (2015). Stamp Seals in the Political Economy of South Asia's Earliest Cities, Ph.D. dissertation, Department of Anthropology, New York University, New York.

Green, A. S. (2016). Finding Harappan seal carvers: An operational sequence approach to identifying people in the past. Journal of Archaeological Science 72: 128-141.

Green, A. S. (2018). Mohenjo-Daro's small public structures: Heterarchy, collective action and a re-visitation of old interpretations with GIS and 3D modelling. Cambridge Archaeological Journal 28: 205-223.

Green, A. S. (2020). Debt and inequality: Comparing the "means of specification" in the early cities of Mesopotamia and the Indus civilization. Journal of Anthropological Archaeology, in press.

Green, A. S., Orengo, H. A., Alam, A., Garcia-Molsosa, A., Green, L. M., Conesa, F., et al. (2019). Rediscovering ancient landscapes: Archaeological survey of mound features from historical maps in northwest India and implications for investigating the large-scale distribution of cultural heritage sites in South Asia. Remote Sensing 11: 26.

Green, A. S., and Petrie, C. A. (n. d.). Cities without subordinates? Upstream urbanization and the Indus civilization. Unpublished manuscript on file, McDonald Institute for Archaeological Research, University of Cambridge, Cambridge.

Green, A. S., and Petrie, C. A. (2018). Landscapes of urbanization and de-urbanization: A large-scale approach to investigating the Indus civilization's settlement distributions in northwest India. Journal of Field Archaeology 43: 284-299.

Gyucha, A. (ed.) (2019). Coming Together: Comparative Approaches to Population Aggregation and Early Urbanization, State University of New York Press, Albany.

Halperin, C. T. (2017). Anthropological archaeology in 2016: Cooperation and collaborations in archaeological research and practice: The year in review. American Anthropologist 119: 284-297.

Hayden, B. (1998). Practical and prestige technologies: The evolution of material systems. Journal of Archaeological Method and Theory 5: 1-55.

Hayden, B., and Cannon, A. (1982). The corporate group as an archaeological unit. Journal of Anthropological Archaeology 1: 132-158.

Hegde, K. T. M., Bhan, K. K., Sonawane, V. H., Krishnan, K., and Shah, D. R. (1990). Excavations at Nageshwar, Gujarat: A Harappan Shell Working Site on the Gulf of Kutch, Maharaja Sayajirao University, Baroda. 
Helms, M. W. (1993). Craft and the Kingly Ideal: Art, Trade, and Power, University of Texas Press, Austin.

Hirth, K. G., and Pillsbury, J. (eds.) (2013). Merchants, Markets, and Exchange in the Pre-Columbian World, Dumbarton Oaks, Washington, DC.

Inomata, T. (2008). Knowledge and belief in artistic production by Classic Maya elites. In Hruby, Z., Flad, R. K., and Bennet, G. (eds.), Rethinking Craft Specialization in Complex Societies: Archaeological Analyses of the Social Meaning of Production. Archeological Papers No. 17, American Anthropological Association, Arlington, VA, pp. 129-141.

Jamison, G. M. (2018). The organization of Indus unicorn seal production: A multi-faceted investigation of technology, skill, and style. In Frenez, D., Jamison, G. M., Law, R., Vidale, M., and Meadow, R. (eds.), Walking with the Unicorn: Social Organization and Material Culture in Ancient South Asia, Archaeopress, Oxford, pp. 269-288.

Jansen, M. (1978). City planning in the Harappa culture. Art and Archaeological Research Papers 1978: $69-74$.

Jansen, M. (1984b). Architectural remains at Mohenjo-daro. In Lal, B. B., and Gupta, P. (eds.), Frontiers of the Indus Civilization, Sir Mortimer Wheeler Commemoration Volume, Books and Books, Delhi, pp. 75-88.

Jansen, M. (1984a). Theoretical aspects of structural analyses for Mohenjo-Daro. In Jansen, M., and Urban, G. (eds.), Interim Reports Vol. 1, Istituto Italiano per il Medio ed Estremo Oriente Roma, Rome, pp. 39-62.

Jansen, M. (1989). Water supply and sewage disposal at Mohenjo-Daro. World Archaeology 21: $177-192$.

Jansen, M. (1993). Mohenjo-Daro: Water Splendour 4500 Years Ago, Frontinus-Gesellschaft, Bergisch.

Jansen, M. (1994). Mohenjo-daro, type site of the earliest urbanization process in South Asia: Ten years of research at Mohenjo-daro, Pakistan and an attempt at synopsis. In Parpola, A., and Koskikallio, P. (eds.), South Asian Archaeology 1993: Proceedings of the Twelfth International Conference of the European Association of South Asian Archaeologists, Soumalainen Tiedeakatemia, Helsinki, pp. 263-280.

Jennings, J., and Earle, T. K. (2016). Urbanization, state formation, and cooperation: A reappraisal. Current Anthropology 57: 474-493.

Joshi, J. P. (1990). Excavations at Surkotada 1971-1972 and exploration in Kutch, Archaeological Survey of India, Delhi.

Joshi, J. P., and Madhu, B. (1993). Excavation at Bhagwanpura, 1975-76 and other explorations \& excavations, 1975-81 in Haryana, Jammu \& Kashmir, and Punjab, Archaeological Survey of India, New Delhi.

Joshi, J. P., Madhu, B., and Ram, J. (1984). The Indus civilization: A reconsideration on the basis of distribution maps. In Lal, B. B., and Gupta, P. (eds.), Frontiers of the Indus Civilization, Sir Mortimer Wheeler Commemoration Volume, Books and Books, Delhi, pp. 510-530.

Joshi, J. P., and Parpola, A. (1987). Corpus of Indus Seals and Inscriptions 1: Collections in India, Suomalainen Tiedeakatemia, Helsinki.

Kennedy, K. (2002). Biological anthropology of human skeletons from Harappa. In Settar, S., and Korisetter, R. (eds.), Indian Archaeology in Retrospect II: Protohistory, Manohar, Delhi pp. 293-316.

Kenoyer, J. M. (1984). Shell industries at Moenjo Daro, Pakistan. In Jansen, M., and Urban, G. (eds.), Interim Reports, Forschungproject, Aachen, pp. 99-116.

Kenoyer, J. M. (1992). Harappan craft specialization and the question of urban segregation and stratification. The Eastern Anthropologist 45: 39-54.

Kenoyer, J. M. (1994). The Harappan state: Was it or wasn't it? In Kenoyer, J. M. (ed.), From Sumer to Meluhha: Contributions to the Archaeology of South and West Asia in Memory of George F. Dales, $J r$., Prehistory Press, Madison, WI, pp. 71-80.

Kenoyer, J. M. (1996). Craft traditions of the Indus civilization and their legacy in modern Pakistan. Lahore Museum Bulletin 9: 1-8.

Kenoyer, J. M. (1997a). Early city-states in South Asia: Comparing the Harappan phase and the early historic period. In Nichols, D. L., and Charlton, T. H. (eds.), The Archaeology of City-States: CrossCultural Approaches, Smithsonian Institution Press, Washington, DC, pp. 51-70.

Kenoyer, J. M. (1997b). Trade and technology of the Indus Valley: New insights from Harappa, Pakistan. World Archaeology 29: 262-280. 
Kenoyer, J. M. (1998). Ancient Cities of the Indus Valley Civilization, Oxford University Press, American Institute of Pakistan Studies, Karachi.

Kenoyer, J. M. (2000). Wealth and socioeconomic hierarchies of the Indus Valley civilization. In Richards, J., and Van Buren, M. (eds.), Order, Legitimacy, and Wealth in Ancient States, Cambridge University Press, Cambridge, pp. 88-109.

Kenoyer, J. M. (2006). Cultures and societies of the Indus tradition. In Tharpar, R. (ed.), Historical Roots in the Making of the Aryan, National Book Trust, New Delhi, pp. 21-49.

Kenoyer, J. M. (2008). Indus urbanism: New perspectives on its origin and character. In Marcus, J., and Sabloff, J. A. (eds.), The Ancient City: New Perspectives on Urbanism in the Old and New World, School for Advanced Research Press, Santa Fe, NM, pp. 185-208.

Kenoyer, J. M. (2010). Measuring the Harappan world: Insights into the Indus order and cosmology. In Morley, I., and Renfrew, C. (eds.), The Archaeology of Measurement: Comprehending Heaven, Earth and Time in Ancient Societies, Cambridge University Press, New York, pp. 106-121.

Kenoyer, J. M. (2012). Households and neighborhoods of the Indus tradition: An overview. In Parker, B. J., and Foster, C. P. (eds.), New Perspectives on Household Archaeology, Eisenbrauns, Winona Lake, IN, pp. 373-406.

Kenoyer, J. M. (2013). Iconography of the Indus unicorn: Origins and legacy. In Abraham, S. A., Gullapalli, P., Raczek, T. P., and Rizvi, U. Z. (eds.), Connections and Complexity, Left Coast Press, Walnut Creek, CA, pp. 107-126.

Kenoyer, J. M., and Meadow, R. H. (2016). Excavations at Harappa, 1986-2010: New insights on the Indus civilization and Harappan burial traditions. In Robbins Schug, G., and Walimbe, S. R. (eds.), A Companion to South Asia in the Past, John Wiley and Sons, Hoboken, NJ, pp. 145-168.

Kenoyer, J. M., Vidale, M., and Bhan, K. K. (1994). Carnelian bead production in Khambhat, India: An ethnoarchaeological study. In Allchin, B. (ed.), Living Traditions: Studies in the Ethnarchaeology of South Asia, Oxford and IBH, New Delhi, pp. 281-306.

Kenoyer, M., and Meadow, R. H. (2010). Inscribed objects from Harappa excavations 1986-2007. In Parpola, A., Pande, B. M., and Koskikallio, P. (eds.), Corpus of Indus Seals and Inscriptions 3: New Material, Untraced Objects and Collections Outside India and Pakistan Part 1: Mohenjo-daro and Harappa, Soumalainen Tiedeakatemia, Helsinki, pp. xliv-lviii.

Khan, F. A. (1965). Excavations at Kot Diji. Pakistan Archaeology 2: 1-119.

Kharakwal, J. S. (ed.) (2012). Excavation at Kanmer: 2005/06-2008/09: Kanmer Archäological Research Project-An Indo-Japanese Collaboration, Indus Project, Research Institute for Humanity and Nature, Kyoto, Japan.

Kohler, T. A., and Smith, M. E. (eds.) (2018). Ten Thousand Years of Inequality, University of Arizona Press, Tucson.

Kohler, T. A., Smith, M. E., Bogaard, A., Feinman, G. M., Peterson, C. E., Betzenhauser, A., et al. (2017). Greater post-Neolithic wealth disparities in Eurasia than in North America and Mesoamerica. Nature 551: 619-622.

Konasukawa, A., and Koiso, M. (2018). The size of Indus seals and its significance. In Frenez, D., Jamison, G. M., Law, R., Vidale, M., and Meadow, R. (eds.), Walking with the Unicorn: Social Organization and Material Culture in Ancient South Asia, Archaeopress, Oxford, pp. 289-314.

Kumar, M. (2009). Harappan settlements in the Ghaggar-Yamuna divide. In Osada, T., and Uesugi, A. (eds.), Linguistics, Archaeology and the Human Past, Occasional Paper 7, Research Institute for Humanity and Nature, Kyoto, pp. 1-24.

Lahiri, N. (1990). Harappa as a centre of trade and trade routes: A case study of the resource-use, resource-access and lines of communication in the Indus civilization. The Indian Economic and Social History Review 27: 405-444.

Lahiri, N. (2005). Finding Forgotten Cities: How the Indus Civilization was Discovered, Permanent Black, Delhi.

Lal, B. B. (1993). A glimpse of the social stratification and political set-up of the Indus civilization. In Possehl, G. L., and Tosi, M. (eds.), Harappan Studies, Oxford and IBH Publishing, Delhi, pp. 63-71.

Lal, B. B. (2003). Excavations at Kalibangan, the Early Harappans, 1960-1969, Archaeological Survey of India, Delhi.

Lal, B. B., Joshi, J. P., Bala, M., Sharma, A. K. and Ramachandran, K. S. (2015). Excavations at Kalibangan: The Harappans (1960-69): Part 1, Archaeological Survey of India, Delhi. 
Laursen, S., and Steinkeller, P. (2017). Babylonia, the Gulf Region, and the Indus: Archaeological and Textual Evidence for Contact in the Third and Early Second Millennium BC, Eisenbrauns, Winona Lake, IN.

Laursen, S. T. (2010). The westward transmission of Indus Valley sealing technology: Origin and development of the "gulf type" seal and other administrative technologies in early Dilmun, c. 2100-200. Arabian Archaeology and Epigraphy 21: 96-134.

Law, R. (2003). Potential steatite sources for the Indus civilization. In Halim, M. A. (ed.), Indus Valley Civilization: Collection of Papers Presented in the International Colloquium on Indus Valley Civilization at Islamabad (6-8 April 2001), Ministry of Culture, Islamabad, pp. 158-167.

Law, R. (2011). Inter-Regional Interaction and Urbanism in the Ancient Indus Valley: A Geological Provenience Study of Harappa's Rock and Mineral Assemblage, Research Institute for Humanity and Nature, Kyoto.

Lawrence, D., and Wilkinson, T. J. (2015). Hubs and upstarts: Pathways to urbanism in the northern Fertile Crescent. Antiquity 89: 328-44.

Lee, H., Waghmare, P., Kim, Y., Hong, J. H., Yadav, Y., Jadhav, N., Shin, D. H., and Shinde, V. S. (2019). Traumatic injury in a cranium found at Rakhigarhi cemetery of Harappan civilization as anthropological evidence of interpersonal violence. Journal of Archaeological Science: Reports 23: $362-367$.

Leppard, T. P. (2019). Social complexity and social inequality in the prehistoric Mediterranean. Current Anthropology 60: 283-308.

Lightfoot, E., Jones, P. J., Joglekar, P. P., Tames-Demauras, M., Smith, E., Muschinski, J., et al. (2020). Feeding the herds: Stable isotope analysis of animal diet and its implication for understanding social organisation in the Indus Civilisation, Northwest India. Archaeological Research in Asia 24: 2352-2267.

Lovell, N. C. (2016). Bioarchaeology of the Indus Valley civilization: Biological affinities, paleopathology, and chemical analyses. In Robbins Schug, G., and Walimbe, S. R. (eds.), A Companion to South Asia in the Past, John Wiley and Sons, Hoboken, NJ, pp. 169-186.

Mackay, E. (1931). Seals, seal impressions, and copper tablets, with tabulation. In Marshall, J. (ed.), Mohenjo-Daro and the Indus Civilization, Arthur Prosbain, London, pp. 370-405.

Mackay, E. (1938). Further Excavations at Mohenjo-daro, Being an Official Account of Archaeological Excavations at Mohenjo-daro Carried Out by the Government of India between the Years 1927 and 1931, Manager of Publications, Delhi.

Mackay, E. (1943). Chanhu-Daro Excavations 1935-36, Varanasi, New Delhi.

Madella, M., and Fuller, D. Q. (2006). Palaeoecology and the Harappan civilisation of South Asia: A reconsideration. Quaternary Science Reviews 25: 1283-1301.

Malik, S. C. (1968). Indian Civilization: The Formative Period, Indian Institute of Advanced Study, Simla.

Marshall, J. (ed.) (1931). Mohenjo-Daro and the Indus Civilization, Arthur Prosbain, London.

Marx, K. (1976). Capital: A Critique of Political Economy, Vintage Books, New York.

Masih, F. (2018). Ganweriwala-A new perspective. In Frenez, D., Jamison, G. M., Law, R., Vidale, M., and Meadow, R. (eds.), Walking with the Unicorn: Social Organization and Material Culture in Ancient South Asia, Archaeopress, Oxford, pp. 375-381

McCorriston, J. (1997). The fiber revolution: Textile extensification, alienation, and social stratification in ancient Mesopotamia. Current Anthropology 38: 517-535.

McGuire, R. H., and Walker, M. (1999). Class confrontations in archaeology. Historical Archaeology 33: 159-183.

McIntosh, R. (2005a). Ancient Middle Niger, Cambridge University Press, Cambridge.

McIntosh, S. K. (2005b). Beyond Chiefdoms: Pathways to Complexity in Africa, Cambridge University Press, Cambridge.

Meadow, R. H. (1998). Pre- and proto-historic agricultural and pastoral transformations in northwestern South Asia. The Review of Archaeology 19: 12-21.

Meadow, R. H., and Kenoyer, J. M. (1997). Excavations at Harappa 1994-1995: New perspectives on the Indus script, craft activities, and city organization. In Allchin, R., and Allchin, B. (eds.), South Asian Archaeology 1995, IBH publishing and Oxford, New Delhi, pp. 139-172.

Meadow, R. H., and Kenoyer, J. M. (2005). Excavations at Harappa 2000-2001: New insights on chronology and city organization. In Jarrige, C., and Lefèvre, V. (eds.), South Asian Archaeology 2001, Centre National de la Recherche Scientifique, Paris, pp. 207-225. 
Meadow, R. H., and Patel, A. (2003). Prehistoric pastoralism in northwestern South Asia from the Neolithic through Harappan period. In Weber, S. A., and Belcher, W. R. (eds.), Indus Ethnobiology, Lexington Books, Lanham, MD, pp. 65-94.

Menon, J. (2008). Archaeological problems with specialization. Studies in History 24: 137-157.

Miller, D. (1985). Ideology and the Harappan civilization. Journal of Anthropological Archaeology 4: 34-71.

Miller, H. M.-L. (2000). Reassessing the urban atructure of Harappa: Evidence for craft production distribution. In Taddei, M., and De Marco, G. (eds.), South Asian Archaeology 1997, Istituto Italiano per l'Africa e L'Oriente, Rome, pp. 77-100.

Miller, H. M.-L. (2006). Water supply, labor requirements, and land ownership in Indus floodplain agricultural systems. In Marcus, J., and Stanish, C. (eds.), Agriculture and Irrigation in Archaeology, Cotsen Institute of Archaeology, University of California, Los Angeles, pp. 92-128.

Miller, H. M.-L. (2007). Archaeological Approaches to Technology, Academic Press, New York.

Miller, H. M.-L. (2008a). Issues in the determination of ancient value systems: The role of talc (steatite) and faience in the Indus civilization. In Olijdam, E., and Spoor, R. H. (eds.), Intercultural Relations between South and Southwest Asia: Studies in Commemoration of E. C. L. During Caspers (1934-1996), Archaeopress, Oxford, pp. 145-157.

Miller, H. M.-L. (2008b). The Indus talc-faience complex. In Raven, E. M. (ed.), South Asian Archaeology 1999, Egbert Forsten, Groningen, pp. 111-132.

Miller, H. M.-L. (2013). Weighty matters: Evidence for unity and regional diversity from the Indus civilization weights. In Abraham, S. A., Gullapalli, P., Raczek, T. P., and Rizvi, U. Z. (eds.), Connections and Complexity, Left Coast Press, Walnut Creek, CA, pp. 161-176.

Miller, H. M.-L. (2015). Surplus in the Indus civilization, agricultural choices, social relations, political effects. In Morehart, C. T., and De Lucia, K. (eds.), Surplus: The Politics of Production and the Strategies of Everyday Life, University Press of Colorado, Boulder, pp. 97-119.

Miller, L. (2003). Secondary products and urbanism in South Asia: The evidence for traction at Harappa. In Weber, S. A., Belcher, W., and Miller, L. J. (eds.), Indus Ethnobiology: New Perspectives from the Field, Lexington Books, Lanham, MD, pp. 251-326.

Morris, E. F. (2014). (Un)dying loyalty: Meditations on retainer sacrifice in ancient Egypt and elsewhere. In Campbell, R. (ed.), Violence and Civilization: Studies of Social Violence in History and Prehistory, Oxbow Books, Oxford, pp. 61-93.

Mosher, M. S. (2017). The Architecture of Mohenjo-Daro as Evidence for the Organization of Indus Civilization Neighbourhoods, Ph.D. dissertation, Department of Anthropology, University of Toronto, Toronto.

Mughal, M. R. (1997). Ancient Cholistan: Archaeology and Architecture, Ferozsons, Lahore.

Mughal, M. R., Khan, G. M., Iqbal, F., Hassan, M., and Khan, M. A. (1996). Archaeological sites and monuments in Punjab. Preliminary results of explorations: 1992-96. Pakistan Archaeology, Special Number 29(1994-1996): 1-474.

Nash, D. J. (2019). Craft production as an empowering strategy in an emerging empire. Journal of Anthropological Research 75: 328-360.

Nath, A. (1998). Rakhigarhi: A Harappan metropolis in the Sarasvati-Drishadvati divide. Puratattva 28: 39-45.

Nath, A. (1999). Further excavations at Rakhigarhi. Puratattva 29: 46-49.

Nath, A. (2001). Rakhigarhi: 1999-2000. Puratattva 31: 43-45.

Nath, A., Walimbe, S. R., Garge, T., Mushrif-Tripathy, V., Dehuri, R., and Malik, A. (2015). Harappan internments at Rakhigarhi, Haryana. Man and Environment XL: 9-32.

Netting, R. M. (1993). Smallholders, Householders: Farm Families and the Ecology of Intensive, Sustainable Agriculture, Stanford University Press, Stanford.

Oka, R., Ames, N., Chesson, M., Kuijit, I., Chapurukha, K., Gogte, V., and Dandekar, A. (2018). Dreaming beyond Gini methodological steps toward a composite archaeological inequality index. In Kohler, T. A., and Smith, M. E. (eds.), Ten Thousand Years of Inequality, University of Arizona Press, Tucson, pp. 67-95.

Oka, R., and Kusimba, C. M. (2008). The archaeology of trading systems, part 1: Towards a new trade synthesis. Journal of Archaeological Research 16: 339-395.

Olson, M. (1965). The Logic of Collective Action: Public Goods and the Theory of Groups, Harvard University Press, Cambridge, MA.

Orengo, H. A., Conesa, F. C., Garcia, A., Green, A. S., Madella, M., and Petrie, C. A. (2020). Automated detection of archaeological mounds using machine-learning classification of multisensor 
and multitemporal satellite data. Proceedings of the National Academy of the Sciences 117: $18240-18250$.

Ostrom, E. (2000). Collective action and the evolution of social norms. Journal of Economic Perspectives 14: $137-158$.

Pal, J. (2014). Bones of contention: A re-evaluation of the sexing of skeletons at the site of Lothal. Proceedings of the Indian History Congress 75: 1167-1172.

Parikh, D., and Petrie, C. A. (2019). 'We are inheritors of a rural civilisation': Rural complexity and the ceramic economy in the Indus civilisation in northwest India. World Archaeology 51: 252-272.

Parmar, N. (2012). Protohistoric Investigations in the Bhiwani District of Haryana, Ph.D. dissertation, Department of Archaeology, Deccan College Post Graduate and Research Institute, Pune.

Parmar, N., Sharan, A., Pawar, V., and Kumar, V. (2013). Harappan settlement system and economic status in the semi arid zone, Bhiwani District, Haryana. Heritage Journal of Multidisciplinary Studies in Archaeology 1: 515-538.

Parpola, A. (1994). Deciphering the Indus Script, Cambridge University Press, Cambridge.

Parpola, A., Pande, B. M., and Koskikallio, P. (2010). Corpus of Indus Seals and Inscriptions, Volume 3: New Material, Untraced Objects, and Collections Outside India and Pakistan, Suomalainen Tiedeakatemia, Helsinki.

Patel, A., Allchin, R., and Allchin, B. (1997). The Pastoral Economy of Dholavira: A First Look at Animals and Urban Life in Third Millennium Kutch, Science Publishers, Oxford, and IBH Publishing, New Delhi.

Pauketat, T. R. (2007). Chiefdoms and Other Archaeological Delusions, AltaMira Press, Lanham, MD.

Pawar, V. (2012). Archaeological Settlement Pattern of Hanumangarh District (Rajasthan), Department of History, Maharshi Dayanand University, Rohtak.

Petrie, C. A. (2013). South Asia. In The Oxford Handbook of Cities in World History, Oxford University Press, Oxford, pp. 83-104.

Petrie, C. A. (2017). Crisis, what crisis? Adaptation, resilience and transformation in the Indus civilisation. In Cunningham, T. F., and Driessen, J. (eds.), Crisis to Collapse: The Archaeology of Social Breakdown, Presses Universitaires de Louvain, Louvain-la-Neuve, pp. 43-64.

Petrie, C. A. (2019). Diversity, variability, adaptation and "fragility" in the Indus civilization. In Yoffee, N. (ed.), The Evolution of Fragility: Setting the Terms, McDonald Institute for Archaeological Research, Cambridge, pp. 109-133.

Petrie, C. A., and Bates, J. (2017). 'Multi-cropping,' intercropping and adaptation to variable environments in Indus South Asia. Journal of World Prehistory 30: 81-130.

Petrie, C. A., Bates, J., Higham, T., and Singh, R. N. (2016). Feeding ancient cities in South Asia: Dating the adoption of rice, millet and tropical pulses in the Indus civilisation. Antiquity 90: 1489-1504.

Petrie, C. A., and Lynam, F. (2020). Revisiting settlement contemporaneity and exploring stability and instability: Case studies from the Indus civilization. Journal of Field Archaeology 45: 1-15.

Petrie, C. A., Parikh, D., Green, A. S., and Bates, J. (2018). Looking beneath the veneer. Thoughts about environmental and cultural diversity in the Indus civilization. In Frenez, D., Jamison, G. M., Law, R., Vidale, M., and Meadow, R. (eds.), Walking with the Unicorn: Social Organization and Material Culture in Ancient South Asia, Archaeopress, Oxford, pp. 453-474.

Petrie, C. A., Singh, R. N., Bates, J., Dixit, Y., French, C. A. I., Hodell, D. A., et al. (2017). Adaptation to variable environments, resilience to climate change: Investigating Land, Water and Settlement in Indus northwest India. Current Anthropology 58: 1-30.

Piggott, S. (1950). Prehistoric India to 1000 BC, Penguin Books, Baltimore.

Pittman, H. (1994). Towards an understanding of the role of glyptic imagery in the administrative systems of proto-literate greater Mesopotamia. In Ferioli, P., Fissori, G. G., and Frangipane, M. (eds.), Archives Before Writing, Ministero per I Beni Culturali e Ambientali, Turin, pp. 177-203.

Pittman, H. (2013). New evidence for interaction between the Iranian Plateau and the Indus Valley: Seals and sealings from Konar Sandal South. In Abraham, S. A., Gullapalli, P., Raczek, T. P., and Rizvi, U. Z. (eds.), Connections and Complexity: New Approaches to the Archaeology of South Asia, Left Coast Press, Walnut Creek, CA, pp. 63-90.

Pokharia, A. K., Kharakwal, J. S., and Srivastava, A. (2014). Archaeobotanical evidence of millets in the Indian subcontinent with some observations on their role in the Indus civilization. Journal of Archaeological Science 42: 442-455.

Pollock, S. (1999). Ancient Mesopotamia: The Eden That Never Was, Cambridge University Press, Cambridge. 
Porčić, M. (2019). Evaluating social complexity and inequality in the Balkans between 6500 and 4200 BC. Journal of Archaeological Research 27: 335-390.

Porter, A. (2012). Mobile Pastoralism and the Formation of Near Eastern Civilizations, Cambridge University Press, Cambridge.

Possehl, G. L. (1986). Kulli: An Exploration of Ancient Civilization in Asia, Carolina Academic Press, Durham, NC.

Possehl, G. L. (1998). Sociocultural complexity without the state: The Indus civilization. In Feinman, G. M., and Marcus, J. (eds.), Archaic States, School of American Research Press, Santa Fe, NM, pp. 261-292.

Possehl, G. L. (1999). Indus Age: The Beginnings, University of Pennsylvania Press, Philadelphia.

Possehl, G. L. (2002). The Indus Civilization: A Contemporary Perspective, AltaMira Press, Walnut Creek, CA.

Possehl, G. L., and Herman, C. F. (1990). The Sorath Harappan: A new regional manifestation of the Indus Urban phase. In Taddei, M. (ed.), South Asian Archaeology 1987, Istituto Italiano per il Medio ed Estremo Oriente, Rome, pp. 295-319.

Prabhakar, V. N. (2018). Decorated carnelian beads from the Indus civilization site of Dholavira (Great Rann of Kachchha, Gujarat). In Frenez, D., Jamison, G. M., Law, R., Vidale, M., and Meadow, R. (eds.), Walking with the Unicorn: Social Organization and Material Culture in Ancient South Asia, Archaeopress, Oxford, pp. 477-489.

Pracchia, S., Tosi, M., and Vidale, M. (1985). Craft industries at Moenjo-daro. In Schotsmans, J., and Taddei, M. (eds.), South Asian Archaeology 1983, Istituto Universitario Orientale Dipartimento di Studi Asiatici, Naples, pp. 207-247.

Preziosi, D. (1983). Minoan Architectural Design, Mouton, Berlin.

Raczek, T. P. (2016). The Ahar culture and others: Social spectrums of the Mewar Plain. In Robbins Schug, G., and Walimbe, S. R. (eds.), A Companion to South Asia in the Past, John Wiley and Sons, Hoboken, NJ, pp. 225-239.

Rahmstorf, L. (2019). Scales, weights and weight-regulated artefacts in Middle and Late Bronze Age Britain. Antiquity 93: 1197-1210.

Rajesh, S. V., Krishnan, K., Ajithprasad, P., and Madella, M. (2013). Pre-Prabhas assemblage from Gujarat, western India. Heritage: Journal of Multidisciplinary Studies in Archaeology 1: 181-209.

Rajesh, S. V. (2011). A Comprehensive Study of the Regional Chalcolithic Cultures of Gujarat, Ph.D. dissertation, Department of Archaeology and Ancient History, Maharaja Sayajirao University of Baroda, Baroda.

Rao, S. R. (1973). Lothal and the Indus Civilization, G. G. Pathare at Popular Press, Bombay.

Rao, S. R. (1979). Lothal: A Harappan Port Town: 1955-1962, Archaeological Survey of India, New Delhi.

Ratnagar, S. (2004). Trading Encounters: From the Euphrates to the Indus in the Bronze Age, 2nd ed., Oxford University Press, New Delhi.

Ratnagar, S. F. (1991). Enquiries into the Political Organization of Harappan Society, Ravish Publishers, Pune.

Ratnagar, S. F. (2016). Harappan Archaeology: Early State Perspectives, Primus Books, Delhi.

Rissman, P. (1988). Public displays and private values: A guide to buried wealth in Harappan archaeology. World Archaeology 20: 209-228.

Rissman, P. (1989). The organization of stamp seal production in the Harappan civilization. In Kenoyer, J. M. (ed.), Old Problems-New Perspectives in the Archaeology of South Asia, Wisconsin Archaeological Reports, Madison, pp. 159-180.

Rizvi, U. Z. (2007). Configuring the Space in between: Redefining the Ganeshwar Jodhpura Cultural Complex in Northeastern Rajasthan, India, Ph.D. dissertation, Department of Anthropology, University of Pennsylvania, Philadelphia.

Rizvi, U. Z. (2011). Subjectivity and spatiality in Indus urban forms: Mohenjo-Daro, the body, and the domestication of waste. In Johansen, P. G., and Bauer, A. M. (eds.), The Archaeology of Politics: The Materiality of Political Practice and Action in the Past, Cambridge Scholars, Newcastle, pp. 221-244.

Rizvi, U. Z. (2015). Crafting resonance: Empathy and belonging in ancient Rajasthan. Journal of Social Archaeology 15: 254-273.

Rizvi, U. Z. (2018). The Affect of Crafting: Third Millennium BCE Copper Arrowheads from Ganeshwar, Rajasthan, Archaeopress, Oxford. 
Robb, J., and Pauketat, T. R. (eds.) (2013). Big Histories, Human Lives: Tackling Problems of Scale in Archaeology, School for Advanced Research Press, Santa Fe, NM.

Robbins Schug, G. (n.d.). Indus mortuary behavior: Between action and symbolic meaning. Unpublished manuscript on file, Department of Anthropology, Appalachian State University, Boone.

Robbins Schug, G., and Blevins, K. E. (2016). The center cannot hold: A bioarchaeological perspective on environmental crisis in the second millennium BCE, South Asia. In Robbins Schug, G., and Walimbe, S. R. (eds.), A Companion to South Asia in the Past, John Wiley and Sons, Hoboken, NJ, pp. 255-273.

Robbins Schug, G., Blevins, K. E., Cox, B., Gray, K., and Mushrif-Tripathy, V. (2013). Infection, disease, and biosocial processes at the end of the Indus civilization. PLOS ONE 8: e84814.

Robbins Schug, G., Gray, K., Mushrif-Tripathy, V., and Sankhyan, A. R. (2012). A peaceful realm? Trauma and social differentiation at Harappa. International Journal of Paleopathology 2: $136-147$.

Robbins Schug, G., and Walimbe, S. R. (2016). Introduction. In Robbins Schug, G., and Walimbe, S. R. (eds.), A Companion to South Asia in the Past, John Wiley and Sons, Hoboken, NJ, pp. 1-10.

Roux, V. (1999). Ethnoarchaeology and the generation of referential models: The case of Harappan carnelian beads. In Roux, V. (ed.), Urgeschichtliche Materialhefte, Mo Vince Verlag, Tübingen, pp. $153-169$.

Roux, V. (2003). Ceramic standardization and intensity of production: Quantifying degrees of specialization. American Antiquity 68: 768-782.

Sarcina, A. (1979). A statistical assessment of house patterns at Mohenjo-Daro. Mesopotamia 13-14: 155-199.

Sastri, K. N. (1965). New Light on the Indus Civilization: Disposal of the Dead, the Aryan Problem, and the Artha Veda, Atma Ram and Sons, Delhi.

Schortman, E. M., and Urban, P. A. (2004). Modeling the roles of craft production in ancient political economies. Journal of Archaeological Research 12: 185-226.

Schortman, E. M., and Urban, P. A. (2011). Networks of Power: Political Relations in the Late Postclassic Naco Valley, Honduras, University Press of Colorado, Boulder.

Service, E. R. (1975). Origins of the State and Civilization: The Process of Cultural Evolution, W. W. Norton, New York.

Shaffer, J. G. (1987). Cultural developments in the eastern Punjab. In Jacobson, J. (ed.), Studies in the Archaeology of India and Pakistan, Aris and Phillips, Warminster, pp. 196-236.

Shaffer, J. G. (1992). The Indus Valley, Baluchistan, and Helmand traditions: Neolithic through Bronze Age. In Ehrich, R. (ed.), Chronologies in Old World Archaeology Volume 1, University of Chicago Press, Chicago, pp. 441-464.

Shah, S. G. M., and Parpola, A. (1991). Corpus of Indus Seals and Inscriptions, 2: Collections in Pakistan, Suomalainen Tiedeakatemia, Helsinki.

Sharan, A. (2018). Archaeological Settlement Pattern of Sangrur and Mansa Districts (Punjab), Ph.D. dissertation, Department of History, Maharshi Dayanand University, Rohtak.

Sharan, A., Pawar, V., and Parmar, N. (2013). An archaeological reconnaissance of the proto-historic settlements in Mansa District, Punjab. Heritage Journal of Multidisciplinary Studies in Archaeology 1: $500-514$.

Sharma, A. K. (1999). The Departed Harappans of Kalibangan, Sundeep Prakashan, New Delhi.

Sher, G. M., and Vidale, M. (1985). Surface evidence of craft activity at Chanhu-daro, March 1984. Estratto da Annali dell'Istituto Universitario Orientale 45: 1-28.

Sherratt, A. (1981). Plough and pastoralism: Aspects of the secondary products revolution. In Isaac, G. L., and Hammond, N. (eds.), Pattern of the Past: Studies in Honour of David Clarke, Cambridge University Press, Cambridge, pp. 155-199.

Shinde, V. (1992). Padri and the Indus civilization. South Asian Studies 8: 55-66.

Shinde, V., Lee, H., Yadav, Y., Waghmare, P., Jadhav, N., Hong, J. H., Kim, Y. J., and Shin, D. H. (2018a). A young couple's grave found in the Rakhigarhi cemetery of the Harappan civilization. Anatomy Cell Biology 51: 200.

Shinde, V. S. (2016). Current perspectives on the Harappan civilization. In Robbins Schug, G., and Walimbe, S. R. (eds.), A Companion to South Asia in the Past, John Wiley and Sons, Chichester, UK, pp. 127-144.

Shinde, V. S., Green, A. S., Parmar, N., and Sable, P. D. (2012). Rakhigarhi and the Harappan civilization: Recent work and new challenges. Bulletin of the Deccan College Research Institute 72/73: 43-53. 
Shinde, V. S., Kim, Y. J., Woo, E. J., Jadhav, N., Waghmare, P., Yadav, Y., et al. (2018b). Archaeological and anthropological studies on the Harappan cemetery of Rakhigarhi, India. PLOS ONE 13: e0192299.

Shinde, V. S., Osada, T., and Kumar, M. (eds.) (2011). Excavations at Farmana: District Rohtak, Haryana, India, 2006-08, Research Institute for Humanity and Nature, Kyoto.

Shinde, V. S., Osada, T., Sharma, M. M., Uesugi, A., Uno, T., Maemoku, H., et al. (2008). Exploration in the Ghaggar Basin and excavations at Girawad, Farmana (Rohtak District) and Mitathal (Bhiwani District), Haryana, India. In Osada, T., and Uesugi, A. (eds.), Linguistics, Archaeology and the Human Past, Indus Project Occasional Paper 3, Research Institute for Humanity and Nature, Kyoto, pp. 77-158.

Shirvalkar, P. (2013). Harappan migrations: A perspective about the Gujarat Harappans. Heritage Journal of Multidisciplinary Studies in Archaeology 1: 301-318.

Singh, R. N., Pandey, A. K., Singh, D. P., Ranjan, A., and Chakradhari, S. (2015). Excavations at Khanak, Bhiwani-2014: A preliminary report. Manaviki 6-7: 815-819.

Singh, R. N., Petrie, C. A., French, C. A. I., Bates, J., Pandey, A. K., Parikh, D., Lancelotti, C., and Redhouse, D. I. (2012). Survey and excavations at Dabli vas Chugta, Hanumangarh District, Rajasthan. Puratattva 42: 133-147.

Singh, R. N., Petrie, C. A., Pawar, V., Pandey, A. K., Neogi, S., Singh, M., et al. (2010). Changing patterns of settlement in the rise and fall of Harappan urbanism and beyond: A preliminary report on the Rakhigarhi hinterland survey 2009. Man and Environment 35: 37-53.

Singh, R. N., Petrie, C. A., Pawar, V., Pandey, A. K., and Parikh, D. (2011). New insights into settlement along the Ghaggar and its hinterland: A preliminary report on the Ghaggar hinterland survey 2010. Man and Environment 36.2: 89-106.

Singh, R. N., Green, A. S., Green, L. M., Ranjan, A., Alam, A., and Petrie, C. A. (2018). Between the hinterlands: Preliminary results from the TwoRains Survey in northwest India (2017). Man and Environment 43.2: 84-102.

Singh, R. N., Green, A. S., Alam, A., and Petrie, C. A. (2019). Beyond the hinterlands: Preliminary results from the TwoRains Survey in northwest India 2018. Man and Environment 44.1: 33-51.

Sinopoli, C. M. (2011). The Political Economy of Craft Production: Crafting Empire in South India, $c$. 1350-1650, Cambridge University Press, Cambridge.

Sinopoli, C. M. (2015). Ancient South Asian cities in their regions. In Yoffee, N. (ed.), The Cambridge World History, Cambridge University Press, Cambridge, pp. 319-342.

Smith, A. T. (2003). The Political Landscape: Constellations of Authority in Early Complex Polities, University of California Press, Berkley.

Smith, M. E. (2009). V. Gordon Childe and the urban revolution: An historical perspective on a revolution in urban studies. Town Planning Review 80: 2-29.

Smith, M. E. (ed.) (2012). The Comparative Archaeology of Complex Societies, Cambridge University Press, Cambridge.

Smith, M. E., Kohler, T. A., and Feinman, G. M. (2018). Studying inequality's deep past. In Kohler, T. A., and Smith, M. E. (eds.), Ten Thousand Years of Inequality, University of Arizona Press, Tucson, pp. 3-38.

Smith, M. L. (2014). The archaeology of urban landscapes. Annual Review of Anthropology 43: 307-323.

Sonawane, V. H. (2018). Harappan shell industry: An overview. Indian Journal of History of Science 53.3: 253-262.

Stein, G. J. (1998). Heterogeneity, power, and political economy: Some current research issues in the archaeology of Old World complex societies. Journal of Archaeological Research 6: 1-44.

Suraj Bhan (1969). Excavations at Mitathal (Hissar) 1968. Journal of Haryana Studies 1: 1-15.

Suraj Bhan (1975). Excavation at Mitathal (1968) and Other Explorations, Kurukshetra University, Kurukshetra.

Suryanarayan, A. (2019). What's Cooking in the Indus Civilisation? Investigating Indus Food through Ceramic Lipid Residue Analysis, Ph.D. dissertation, Department of Archaeology, Univerity of Cambridge, Cambridge.

Tainter, J. A., and Crumley, C. L. (2007). Climate, complexity, and problem solving in the Roman Empire. In Costanza, R., Graumlich, L. J., and Steffen, W. (eds.), Sustainability or Collapse? MIT Press, Cambridge, pp. 61-75.

Teramura, H., and Uno, T. (2006). Spatial analyses of Harappan urban settlements. Ancient Asia 1: 73.

Trigger, B. G. (1974). The archaeology of government. World Archaeology 6: 95-106.

Trigger, B. G. (1989). A History of Archaeological Thought, Cambridge University Press, Cambridge. 
Trigger, B. G. (2003). Understanding Early Civilizations, Cambridge University Press, Cambridge.

Uesugi, A., Nakai, I., Kumar, M., Yamahana, K., Shirataki, J., Toyama, K., and Dangi, V. (2013). A study on faience objects in the Ghaggar Plains during the Urban and post-Urban Indus periods. Report Submitted to harappa.com.

Ur, J. A. (2010). Cycles of civilization in northern Mesopotamia, 4400-2000 BC. Journal of Archaeological Research 18: $387-431$.

Vats, M. S. (1940). Excavations at Harappa: Being an Account of Archaeological Excavations at Harappa Carried Out Between 1920-21 and 1933-34, Munshiram Manoharlal, Delhi.

Vidale, M. (1986). Steatite cutting on glazing: Relational aspects of two technological environments in Harappan urban contexts. East and West 36: 520-525.

Vidale, M. (1989). Specialized producers and urban elites on the role of craft production in Mature Harappan urban contexts. In Kenoyer, J. M. (ed.), Old Problems and New Perspectives in the Archaeology of South Asia, Wisconsin Archaeological Reports, Madison, pp. 171-181.

Vidale, M. (1990). On the structure and the relative chronology of an Harappan industrial site. In Taddei, M., and Callieri, M. (eds.), South Asian Archaeology 1987, Istituto Italiano per il Medio ed Estremo Oriente Roma, Rome, pp. 203-244.

Vidale, M. (2000). The Archaeology of Indus Crafts: Indus Craftspeople and Why We Study Them, Istituto Italiano per l'Africa e l'Oriente, Rome.

Vidale, M. (2005). The short-horned bull on the Indus seals: À symbol of the families in the western trade? In Franke, U., and Weisshaar, H. J. (eds.), South Asian Archaeology 2003, Lindon Soft, Aichwald, pp. 147-157.

Vidale, M. (2010). Aspects of palace life at Mohenjo-Daro. South Asian Studies 26: 59-76.

Vidale, M. (2018a). A "priest king” at Shahr-i Sokhta? Archaeological Research in Asia 15: 110-115.

Vidale, M. (2018b). Heterarchic powers in the ancient Indus cities. Journal of Asian Civilizations 41(2): 1-46.

Vidale, M., and Balista, C. (1988). Towards a geo-archaeology of craft at Moenjodaro. In Jansen, M., and Tosi, M. (eds.), Interim Reports Vol. 3, Istituto Italiano per il Medio ed Estremo Oriente Roma, Rome, pp. 93-108.

Vidale, M., and Miller, H. M.-L. (2000). On the development of Indus technical virtuosity and its relation to social structure. In Taddei, M., and De Marco, G. (eds.), South Asian Archaeology 1997, Istituto Italiano per l'Africa e l'Oriente, Rome, pp. 115-132.

Wailes, B. (1995). A case study of heterarchy in complex societies: Early medieval Ireland and its archaeological implications. In Ehrenreich, R., Crumley, C. L., and Levy, J. E. (eds.), Heterarchy in the Analysis of Complex Societies, Archeological Papers No. 6, American Anthropological Association, Arlington, VA, pp. 55-69

Wankze H. (1984). Axis systems and orientation at Mohenjo-daro. Interim Reports Vol. 2, Istituto Italiano per il Medio ed Estremo Oriente Roma, Rome, pp. 23-32.

Weber, S. A. (1991). Plants and Harappan Subsistence: An Example of Stability and Change from Rojdi, Oxford and IBH Publishing, New Delhi.

Weber, S. A. (1999). Seeds of urbanism: Palaeoethnobotany and the Indus civilization. Antiquity 73: $813-826$.

Weber, S. A. (2003). Archaeobotany at Harappa: Indications for change. In Weber, S. A., and Belcher, W. R. (eds.), Indus Ethnobiology: New Perspectives From the Field, Lexington Books, Lanham, MD, pp. 175-198.

Weber, S., and Kashyap, A. (2016). The vanishing millets of the Indus civilization. Archaeological and Anthropological Sciences 8: 9-15.

Wengrow, D. (2010). What Makes Civilization? The Ancient Near East and the Future of the West, Oxford University Press, Oxford.

Wenke, R. J. (2009). The Ancient Egyptian State: The Origins of Egyptian Culture (c. 8000-2000 $B C)$, Cambridge University Press, Cambridge.

Wheeler, S. M. (1947). Harappa 1946: The defenses and cemetery R37. Ancient India 3: 58-130.

Wheeler, S. M. (1953). The Cambridge History of India: Supplementary Volume, the Indus Civilization, Cambridge University Press, Cambridge.

Wheeler, S. M. (1968). The Indus Civilization, Cambridge University Press, Cambridge.

Wilkins, H. (2005). From massive to flimsy: The declining structural fabric at Mohenjo-Daro. In Franke, U., and Weisshaar, H. J. (eds.), South Asian Archaeology 2003, Lindon Soft, Aichwald, pp. 137-146. 
Wilkinson, T. C. (2014). Tying the Threads of Eurasia: Trans-regional Routes and Material Flows in Transcaucasia, Eastern Anatolia and Western Central Asia, c. 3000-1500 BC, Sidestone Press, Leiden.

Williams, H. (2015). Chapter 15-Towards an archaeology of cremation. In Schmidt, C. W., and Symes, S. A. (eds.), The Analysis of Burned Human Remains, 2nd ed., Academic Press, San Diego, pp. 259-293.

Wright, H. (1977). Recent research on the origin of the state. Annual Review of Anthropology 6: 379-397.

Wright, H. T., and Johnson, G. A. (1975). Population, exchange, and early state formation in southwestern Iran. American Anthropologist 77: 267-289.

Wright, R. (1993). Technological styles: Transforming a natural material into a cultural object. In Lubar, S., and Kingery, W. D. (eds.), History from Things: Essays on Material Culture, Smithsonian Institution Press, Washington, DC, pp. 242-269.

Wright, R. P. (1991). Patterns of technology and the organization of production at Harappa. In Meadow, R. H. (ed.), Harappa Excavations 1986-1900: A Multidisciplinary Approach to Third Millennium Urbanism, Prehistory Press, Madison, WI, pp. 71-88.

Wright, R. P. (2002). The origin of cities. In Ember, M., and Ember, C. R. (eds.), Encyclopedia of Urban Cultures: Cities and Cultures around the World, Grolier, Danbury, pp. 3-11.

Wright, R. P. (2010). The Ancient Indus: Urbanism, Economy and Society, Cambridge University Press, Cambridge.

Wright, R. P. (2012). Perspectives from the Indus: Contexts of interaction in the Late Harappan/posturban period. In Potts, D., and Hellyer, P. (eds.), Fifty Years of Emirates Archaeology, Motivate Publishing, Dubai, pp. 98-109.

Wright, R. P. (2016). Cognitive codes and collective action at Mari and the Indus. In Fargher, L. F., and Espinoza, V. Y. H. (eds.), Alternative Pathways to Complexity; Households, Markets, World Systems, and Political Economy, University Press of Colorado, Boulder, pp. 225-238.

Wright, R. P. (2018). Comparative perspectives and early states revisited. In Brooke, J. L., Strauss, J. C., and Anderson, G. (eds.), State Formations, Cambridge University Press, Cambridge, pp. 73-89.

Wright, R. P., and Garrett, Z. (2018). Engineering feats and consequences: Workers in the night and the Indus civilization. In Gonlin, N., and Nowell, A. (eds.), Archaeology of the Night: Life After Dark in the Ancient World, University Press of Colorado, Boulder, pp. 287-306.

Wright, R. P., Bryson, R. A., and Schuldenrein, J. (2008). Water supply and history: Harappa and the Beas regional survey. Antiquity 82: 37-48.

Wright, R. P., Schuldenrein, J., Khan, M. A., and Malin-Boyce, S. (2003). The Beas River landscape and settlement survey: Preliminary results from the site of Vainiwal. In Franke, U., and Weisshaar, H. J. (eds.), South Asian Archaeology 2003, Lindon Soft, Aichwald, pp. 101-110.

Wright, R. P., Schuldenrein, J., Khan, M. A., and Mughal, M. (2005). The emergence of satellite communities along the Beas drainage: Preliminary results from Lahoma Lal Tibba and Chak Purbane Syal. In Jarrige, C., and Lefèvre, V. (eds.), South Asian Archaeology 2001, Editions Recherché Sur les Civilizations, Paris, pp. 327-336.

Wurst, L. (1999). Internalizing class in historical archaeology. Historical Archaeology 33: 7-21.

Yoffee, N. (2005). Myths of the Archaic State Evolution of the Earliest Cities, States, and Civilizations, Cambridge University Press, Cambridge.

Yoffee, N. (2016). The power of infrastructures: A counternarrative and a speculation. Journal of Archaeological Method and Theory 23: 1053-1065.

Yoffee, N. (2019). The Evolution of Fragility: Setting the Terms, McDonald Institute Monographs, Cambridge.

\section{Bibliography of Recent Literature}

Abraham, S., Gullapalli, P., Raczek, T. P., and Rizvi, U. Z. (eds.) (2013). Connections and Complexity: New Approaches to the Archaeology of South Asia, Left Coast Press, Walnut Creek, CA.

Ameri, M. (2020). Variations on a theme: Iconographic variability in the horned anthropomorphic figures of the Indus civilization. Artibus Asiae 79: 29-50. 
Ceccarelli, A., and Petrie, C. A. (2020). Cultural evolutionary paradigms and technological transformations from the Neolithic up to the Indus urban period in South Asia. In Greaves Andrade, L. R., and Hardy, A. (eds.), Religions, Society, Trade and Kingship: Archaeology and Art in South Asia and Along the Silk Road 3500 BC-5th Century CE, South Asian Archaeology and Art 2016, Dev Publishers, New Delhi, pp. 3-20.

Conesa, F. C., Lobo, A., Alcaina, J., Balbo, A., Madella, M., Rajesh, S. V., and Ajithprasad, P. (2017). Multi-proxy survey of open-air surface scatters in drylands: Archaeological and physico-chemical characterisation of fossilised dunes in North Gujarat (India). Quaternary International 436: 57-75.

Coningham, R., and Manuel, M. (2009). Priest-kings or puritans? Childe and willing subordination in the Indus. European Journal of Archaeology 12: 167-180.

Coningham, R., and Young, R. (2015). The Archaeology of South Asia: From the Indus to Asoka, c. 6500 BCE-200 CE, Cambridge University Press, Cambridge.

Danino, M. (2010). The Lost River: On the Trail of the Sarasvatī, Penguin Books India, New Delhi.

Danino, M. (2016). Aryans and the Indus civilization: Archaeological, skeletal, and molecular evidence. In Robbins Schug, G., and Walimbe, S. R. (eds.), A Companion to South Asia in the Past, John Wiley and Sons, Hoboken, NJ, pp. 205-224.

Farooqui, A., Gaur, A. S., and Prasad, V. (2013). Climate, vegetation and ecology during Harappan period: Excavations at Kanjetar and Kaj, mid-Saurashtra coast, Gujarat. Journal of Archaeological Science 40: 2631-2647.

Frenez, D., Jamison, G., Law, R. W., Vidale, M., and Meadow, R. H. (eds.) (2018). Walking with the Unicorn: Social Organization and Material Culture in Ancient South Asia: Jonathan Mark Kenoy, Felicitation Volume, Archaeopress Archaeology, Summertown, Oxford.

Gupta, A. K., Sharma, J. R., and Sreenivasan, G. (2011). Using satellite imagery to reveal the course of an extinct river below the Thar Desert in the Indo-Pak region. International Journal of Remote Sensing 32: 5197-5216.

Kenoyer, J. M., Price, T. D., and Burton, J. H. (2013). A new approach to tracking connections between the Indus Valley and Mesopotamia: Initial results of strontium isotope analyses from Harappa and Ur. Journal of Archaeological Science 40: 2286-2297.

Lindstrom, K. (2013). Pottery Preferences and Community Dynamics in the Indus Civilization Borderlands, Ph.D. dissertation, Department of Anthropology, University of Wisconsin, Madison.

Méry, S., and Blackmon, J. (2005). Socio-economical patterns of a ceramic container: The Harappan black slipped jar. In Jarrige, C., and Lefèvre, V. (eds.), South Asian Archaeology 2001, Editions Recherché Sur les Civilizations, Paris, pp. 227-235.

Parpola, A. (2015). The Roots of Hinduism: The Early Aryans and the Indus Civilization, Oxford University Press, New York.

Patel, S. (2017). Dynamics of Ceramic Technological Style and Boundaries of the Sorath Harappans. Ph.D. dissertation. Department of Anthropology, New York University, New York.

Petrie, C. A. (ed.) (2013). Ancient Iran and Its Neighbours: Local Developments and Long-Range Interactions in the Fourth Millennium BC, Oxbow Books, Oxford.

Petrie, C. A., and Singh, R. N. (2008). Investigating cultural and geographical transformations from the collapse of Harappan urbanism to the rise of the great early historic cities: A note on the Land, Water, and Settlement Project. South Asian Studies 24: 37-38.

Ratnagar, S. F. (2003). The End of the Great Harappan Tradition, Manohar Publishers, Delhi.

Robbins Schug, G., Walimbe, S. R., and Kennedy, K. A. R. (eds.) (2016). A Companion to South Asia in the Past, John Wiley and Sons, Chichester, UK.

Shinde, V., Narasimhan, V. M., Rohland, N., Mallick, S., Mah, M., Lipson, M., et al. (2019). An ancient Harappan genome lacks ancestry from steppe pastoralists or Iranian farmers. Cell 179: S0092867419309675.

Schuldenrein, J., Wright, R. P., Mughal, M. R., and Khan, M. A. (2004). Landscapes, soils, and mound histories of the Upper Indus Valley, Pakistan: New insights on the Holocene environments near ancient Harappa. Journal of Archaeological Science 31: 777-797.

Thakur, B., Seth, P., Sharma, A., Pokharia, A. K., Spate, M., and Farooqui, S. (2019). Linking past cultural developments to palaeoenvironmental changes from 5000 BP to present: A climate-culture reconstruction from Harshad estuary, Saurashtra, Gujarat, India. Quaternary International 507: 188-196.

Uesugi, A. (ed.) (2018). Current Research on Indus Archaeology, Research Group for South Asian Archaeology, Archaeological Research Institute, Kansai University. 
Valentine, B. (2016). More than origins: Refining migration in the Indus civilization. In Robbins Schug, G., and Walimbe, S. R. (eds.), A Companion to South Asia in the Past, John Wiley and Sons, Hoboken, NJ, pp. 187-204.

Valentine, B., Kamenov, G. D., Kenoyer, J. M., Shinde, V. S., Mushrif-Tripathy, V., Otarola-Castillo, E., and Krigbaum, J. (2015). Evidence for patterns of selective urban migration in the greater Indus Valley (2600-1900 BC): A lead and strontium isotope mortuary analysis. PLOS ONE 10: e0123103.

Weber, S. A., Barela, T., and Lehman, H. (2010). Ecological continuity: An explanation for agricultural diversity in the Indus civilization and beyond. Man and Environment. 35: 62-75.

Publisher's Note Springer Nature remains neutral with regard to jurisdictional claims in published maps and institutional affiliations. 